\title{
IMI - Oral biopharmaceutics tools project - Evaluation of bottom-up PBPK prediction success part 3: Identifying gaps in system parameters by analysing In Silico performance across different compound classes
}

DOI:

10.1016/j.ejps.2016.09.037

\section{Document Version}

Accepted author manuscript

Link to publication record in Manchester Research Explorer

Citation for published version (APA):

Darwich, A., Aarons, L., Galetin, A., Rostami-Hochaghan et al, A., Margolskee, A., Pepin, X., Carlert, S., Hammarberg, M., Hilgendorf, C., Johansson, P., Karlsson, E., Murphy, D., Tannergren, C., Thorn, H., Yasin, M., Mazuir, F., Nicolas, O., Ramusovic, S., Xu, C., ... Abrahmsson, B. (2017). IMI - Oral biopharmaceutics tools project - Evaluation of bottom-up PBPK prediction success part 3: Identifying gaps in system parameters by analysing In Silico performance across different compound classes. European Journal of Pharmaceutical Sciences, 96, 626-642. https://doi.org/10.1016/j.ejps.2016.09.037

\section{Published in:}

European Journal of Pharmaceutical Sciences

\section{Citing this paper}

Please note that where the full-text provided on Manchester Research Explorer is the Author Accepted Manuscript or Proof version this may differ from the final Published version. If citing, it is advised that you check and use the publisher's definitive version.

\section{General rights}

Copyright and moral rights for the publications made accessible in the Research Explorer are retained by the authors and/or other copyright owners and it is a condition of accessing publications that users recognise and abide by the legal requirements associated with these rights.

\section{Takedown policy}

If you believe that this document breaches copyright please refer to the University of Manchester's Takedown Procedures [http://man.ac.uk/04Y6Bo] or contact uml.scholarlycommunications@manchester.ac.uk providing relevant details, so we can investig THEC $\mathrm{N}$. 


\section{Accepted Manuscript}

IMI - Oral biopharmaceutics tools project - Evaluation of bottom-up PBPK prediction success part 3: Identifying gaps in system parameters by analysing In Silico performance across different compound classes

Adam S. Darwich, Alison Margolskee, Xavier Pepin, Leon Aarons, Aleksandra Galetin, Amin Rostami-Hodjegan, Sara Carlert, Maria Hammarberg, Constanze Hilgendorf, Pernilla Johansson, Eva Karlsson, Dónal Murphy, Christer Tannergren, Helena Thörn, Mohammed Yasin, Florent Mazuir, Olivier Nicolas, Sergej Ramusovic, Christine Xu, Shriram M. Pathak, Timo Korjamo, Johanna Laru, Jussi Malkki, Sari Pappinen, Johanna Tuunainen, Jennifer Dressman, Simone Hansmann, Edmund Kostewicz, Handan He, Tycho Heimbach, Fan Wu, Carolin Hoft, Yan Pang, Michael B. Bolger, Eva Huehn, Viera Lukacova, James M. Mullin, Ke X. Szeto, Chester Costales, Jian Lin, Mark McAllister, Sweta Modi, Charles Rotter, Manthena Varma, Mei Wong, Amitava Mitra, Jan Bevernage, Jeike Biewenga, Achiel Van Peer, Richard Lloyd, Carole Shardlow, Peter Langguth, Irina Mishenzon, Mai Anh Nguyen, Jonathan Brown, Hans Lennernäs, Bertil Abrahamsson

PII: $\quad$ S0928-0987(16)30420-1

DOI: $\quad$ doi: $\quad$ 10.1016/j.ejps.2016.09.037

Reference: $\quad$ PHASCI 3743

To appear in:

Received date: 10 May 2016

Revised date: 23 August 2016

Accepted date: $\quad 26$ September 2016

Please cite this article as: Darwich, Adam S., Margolskee, Alison, Pepin, Xavier, Aarons, Leon, Galetin, Aleksandra, Rostami-Hodjegan, Amin, Carlert, Sara, Hammarberg, Maria, Hilgendorf, Constanze, Johansson, Pernilla, Karlsson, Eva, Murphy, Dónal, Tannergren, Christer, Thörn, Helena, Yasin, Mohammed, Mazuir, Florent, Nicolas, Olivier, Ramusovic, Sergej, Xu, Christine, Pathak, Shriram M., Korjamo, Timo, Laru, Johanna, Malkki, Jussi, Pappinen, Sari, Tuunainen, Johanna, Dressman, Jennifer, Hansmann, Simone, Kostewicz, Edmund, He, Handan, Heimbach, Tycho, Wu, Fan, Hoft, Carolin, Pang, Yan, Bolger, Michael B., Huehn, Eva, Lukacova, Viera, Mullin, James M., Szeto, Ke X., Costales, Chester, Lin, Jian, McAllister, Mark, Modi, Sweta, Rotter, Charles, Varma, Manthena, Wong, Mei, Mitra, Amitava, Bevernage, Jan, Biewenga, Jeike, Van Peer, Achiel, Lloyd, Richard, Shardlow, Carole, Langguth, Peter, Mishenzon, Irina, Nguyen, Mai Anh, Brown, Jonathan, Lennernäs, Hans, Abrahamsson, Bertil, IMI - Oral biopharmaceutics tools project - Evaluation of bottom-up PBPK prediction success part 3: Identifying gaps in system parameters by analysing In Silico performance across different compound classes, (2016), doi:10.1016/j.ejps.2016.09.037 


\section{IMI - Oral Biopharmaceutics Tools} project - Evaluation of Bottom-up PBPK Prediction Success Part 3: Identifying Gaps in System Parameters by Analysing In Silico Performance across Different Compound Classes

Adam S. Darwich ${ }^{1}$, Alison Margolskee ${ }^{1}$, Xavier Pepin ${ }^{2,3}$, Leon Aarons $^{1}$, Aleksandra Galetin ${ }^{1}$, Amin Rostami-Hodjegan ${ }^{1,4}$, Sara Carlert ${ }^{5}$, Maria Hammarberg ${ }^{5}$, Constanze Hilgendorf ${ }^{5}$, Pernilla Johansson ${ }^{5}$, Eva Karlsson ${ }^{5}$, Dónal Murphy ${ }^{2}$, Christer Tannergren ${ }^{5}$, Helena Thörn ${ }^{5}$, Mohammed Yasin ${ }^{2}$, Florent Mazuir ${ }^{3}$, Olivier Nicolas ${ }^{3}$, Sergej Ramusovic ${ }^{6}$, Christine Xu ${ }^{7}$, Shriram M. Pathak ${ }^{4}$, Timo Korjamo ${ }^{8}$, Johanna Laru ${ }^{2,8}$, Jussi Malkki ${ }^{8}$, Sari Pappinen ${ }^{8}$, Johanna Tuunainen ${ }^{8}$, Jennifer Dressman ${ }^{9}$, Simone Hansmann ${ }^{9}$, Edmund Kostewicz ${ }^{9}$, Handan $\mathrm{He}^{10}$, Tycho Heimbach ${ }^{10}$, Fan Wu ${ }^{10}$, Carolin Hoft ${ }^{11}$, Yan Pang ${ }^{11}$, Michael B. Bolger ${ }^{12}$, Eva Huehn $^{12}$, Viera Lukacova ${ }^{12}$, James M. Mullin ${ }^{12}$, Ke X. Szeto ${ }^{12}$, Chester Costales ${ }^{13}$, Jian Lin ${ }^{13}$, Mark McAllister $^{14}$, Sweta Modi ${ }^{13}$, Charles Rotter ${ }^{13}$, Manthena Varma ${ }^{14}$, Mei Wong ${ }^{14}$, Amitava Mitra ${ }^{15}$, Jan Bevernage ${ }^{16}$, Jeike Biewenga ${ }^{16}$, Achiel Van Peer ${ }^{16}$, Richard Lloyd ${ }^{17}$, Carole Shardlow $^{17}$, Peter Langguth ${ }^{18}$, Irina Mishenzon ${ }^{18}$, Mai Anh Nguyen ${ }^{18}$, Jonathan Brown $^{19}$, Hans Lennernäs ${ }^{20}$, Bertil Abrahamsson ${ }^{5}$

${ }^{1}$ University of Manchester, United Kingdom

${ }^{2}$ AstraZeneca, United Kingdom

${ }^{3}$ Sanofi, France

${ }^{4}$ Simcyp Ltd, United Kingdom

${ }^{5}$ AstraZeneca, Sweden

${ }^{6}$ Sanofi, Germany

${ }^{7}$ Sanofi, United States

${ }^{8}$ Orion Pharma, Finland

${ }^{9}$ Goethe University Frankfurt am Main, Germany

${ }^{10}$ Novartis, United States

${ }^{11}$ AbbVie, Germany 
${ }^{12}$ Simulations Plus, Inc., United States

${ }^{13}$ Pfizer, United States

${ }^{14}$ Pfizer, United Kingdom

${ }^{15}$ Merck Sharp \& Dohme (MSD), United Kingdom

${ }^{16}$ Janssen, Belgium

${ }^{17}$ GlaxoSmithKline, United Kingdom

${ }^{18}$ Johannes Gutenberg University of Mainz, Germany

${ }^{19}$ Bristol-Myers Squibb, United Kingdom

${ }^{20}$ Uppsala University, Sweden

\section{Graphical Abstract}
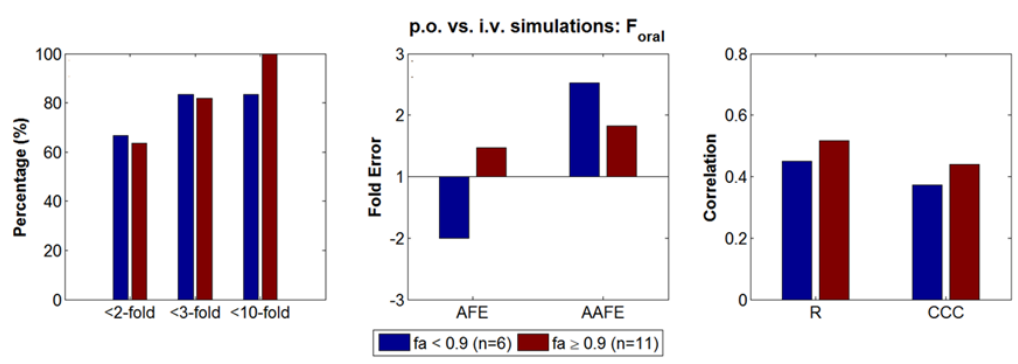

\begin{tabular}{|l|l|}
\hline$\sqrt{ }$ & Areas for Improvement Checklist \\
\hline $\begin{array}{l}\text { Fa less than } 90 \% \text { - improve scaling of } \\
\text { in vitro to } \text { in vivo permeability, and in } \\
\text { silico models of intestinal surface area } \\
\text { and transporters }\end{array}$ \\
\hline $\begin{array}{l}\text { Low Aqueous Solubility and/or High } \\
\text { LogP - improve in silico models and in } \\
\text { vitro availability of biorelevant solubility } \\
\text { and dissolution }\end{array}$ \\
\hline $\begin{array}{l}\text { Acids - improve predictions of CL, Vd } \\
\text { and permeability }\end{array}$ \\
\hline $\begin{array}{l}\text { Weak bases - improve in silico } \\
\text { predictions of precipitation and } \\
\text { availability of } \text { in vitro data }\end{array}$ \\
\hline $\begin{array}{l}\text { No reported LogP - improve } \\
\text { availability of logP measurements }\end{array}$ \\
\hline $\begin{array}{l}\text { Low BP and/or low fup - investigate } \\
\text { influence of blood and plasma binding on } \\
\text { underpredictions of hepatic CL for highly } \\
\text { plasma bound compounds }\end{array}$ \\
\hline
\end{tabular}
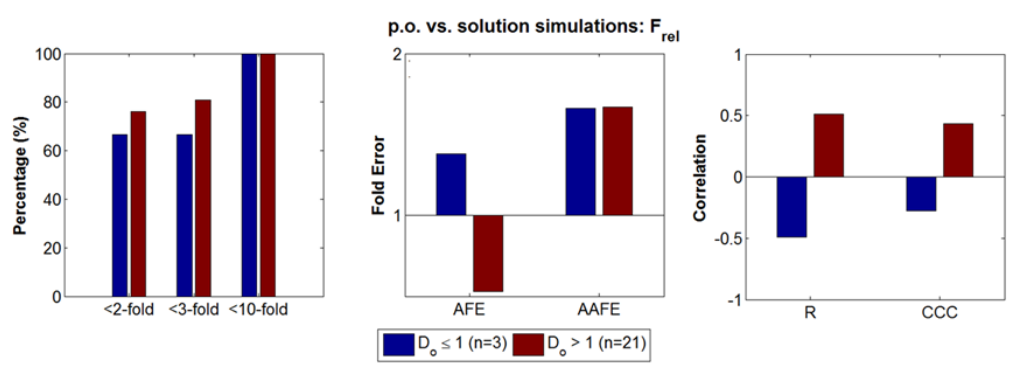

plasma bound compounds

\section{Abstract}

Three Physiologically Based Pharmacokinetic software packages (GI-Sim, Simcyp ${ }^{\circledR}$

Simulator, and GastroPlus ${ }^{\mathrm{TM}}$ ) were evaluated as part of the Innovative Medicine Initiative

Oral Biopharmaceutics Tools project (OrBiTo) during a blinded "bottom-up" anticipation of 
human pharmacokinetics. After data analysis of the predicted vs. measured pharmacokinetics parameters, it was found that oral bioavailability $\left(\mathrm{F}_{\text {oral }}\right)$ was underpredicted for compounds with low permeability, suggesting improper estimates of intestinal surface area, colonic absorption and/or lack of intestinal transporter information. $F_{\text {oral }}$ was also underpredicted for acidic compounds, suggesting overestimation of impact of ionisation on permeation, lack of information on intestinal transporters, or underestimation of solubilisation of weak acids due to less than optimal intestinal model $\mathrm{pH}$ settings or underestimation of bile micelle contribution. $\mathrm{F}_{\text {oral }}$ was overpredicted for weak bases, suggesting inadequate models for precipitation or lack of in vitro precipitation information to build informed models. Relative bioavailability was underpredicted for both high $\log \mathrm{P}$ compounds as well as poorly watersoluble compounds, suggesting inadequate models for solubility/dissolution, underperforming bile enhancement models and/or lack of biorelevant solubility measurements. These results indicate areas for improvement in model software, modelling approaches, and generation of applicable input data.

However, caution is required when interpreting the impact of drug-specific properties in this exercise, as the availability of input parameters was heterogeneous and highly variable, and the modellers generally used the data "as is" in this blinded bottom-up prediction approach.

\section{Keywords:}

Physiologically-based pharmacokinetics (PBPK); modelling and simulation (M\&S); absorption; oral bioavailability $\left(\mathrm{F}_{\text {oral }}\right)$; biopharmaceutics; drug database

\section{Abbreviations:}

$\mathrm{AFE}=$ Average Fold Error 
AAFE $=$ Absolute Average Fold Error

API = Active pharmaceutical ingredient,

$\mathrm{AUC}=$ Area under the curve,

BCS = Biopharmaceutics classification system,

$\mathrm{BE}=$ Bioequivalence

$\mathrm{BP}=$ Blood-to-plasma ratio,

$\mathrm{CCC}=$ Concordance Correlation Coefficient

$\mathrm{CL}=$ Clearance,

$\mathrm{CL} / \mathrm{F}=$ Apparent clearance

$\mathrm{C}_{\max }=$ Maximum concentration,

$\mathrm{D}_{\mathrm{o}}=$ Dose number,

$\mathrm{f}_{\mathrm{a}}=$ Fraction absorbed,

$\mathrm{FE}=$ Fold Error

FIM = First In Man

$F_{\text {oral }}=$ Absolute oral bioavailability,

$\mathrm{F}_{\text {rel }}=$ Relative bioavailability,

$\mathrm{fu}_{\mathrm{p}}=$ fraction unbound in plasma,

$\mathrm{GI}=$ Gastro-Intestinal

$\mathrm{IMI}=$ Innovative Medicines Initiative, 
i.v. $=$ Intravenous,

$\mathrm{IR}=\mathrm{Immediate}$ release

$\log \mathrm{P}=\mathrm{Log}$ arithm of the octanol/water partition coefficient,

$\log \mathrm{D}_{\mathrm{pH}}=\operatorname{Logarithm}$ of the octanol/water partition coefficient at a given $\mathrm{pH}$,

MAT $=$ Mean Absorption Time

MTD = Maximal Tolerated Dose

MTT $=$ Mean Transit Time)

MRT $=$ Mean Residence Time

MW = Molecular weight

$<$-fold $=\%$ APIs within n-fold

PAC $=$ Post Approval Changes

PBPK = Physiologically-based pharmacokinetic,

$\mathrm{PK}=$ Pharmacokinetic

p.o. $=$ per oral,

$\mathrm{QbD}=$ Quality by Design

$\mathrm{R}=$ Pearson correlation coefficient

$\mathrm{SME}=$ Small or Medium Enterprise

$\mathrm{t}_{\max }=$ Time at maximum concentration,

$\mathrm{V}_{\mathrm{d}}=$ Volume of distribution 
$\mathrm{V}_{\mathrm{d}} / \mathrm{F}=$ Apparent volume of distribution,

\section{Introduction}

The oral route is the most favourable route for drug administration due to its ease of administration and minimal invasiveness. However, orally administered drug products are exposed to a number of potential barriers between administration and systemic exposure, such as dissolution of solid particles and potential precipitation in the gut lumen, permeation through the gut membrane, and intestinal and hepatic first pass metabolism. These processes can have a big impact on the ability to predict in vivo performance of drug products. The ability to anticipate the impact of these processes is of great importance in drug and formulation development.

The Innovative Medicines Initiative (IMI) Oral Biopharmaceutical Tools (OrBiTo) project aims to improve upon knowledge of oral drug absorption through the development of new methodologies and refinement of existing tools available in oral biopharmaceutical development. Through four workpackages (WP1-4), the OrBiTo project aims to improve on the tools for evaluating physico-chemical characterisations of active pharmaceutical ingredients (APIs), the development and characterisation of drug product formulations, better understanding of the human intestinal environment, and the in silico models for integrating these different aspects into quantitative and qualitative predictions of oral drug exposure (Lennernas et al., 2014). In our previous work we demonstrated the setup of the OrBiTo database of APIs and an overview of the results of the simulation exercise to evaluate the predictive performance of three established PBPK software packages (Margolskee et al. Part 1 - Submitted; Margolskee et al. - Part 2 - Submitted). 
Here we present an analysis of the prediction success with a focus on the impact of compound specific properties and other factors that may influence the outcome of predictions of oral drug exposure. For example, acid/base nature, as well as lipophilicity, are thought to play important roles in dissolution, absorption, and disposition, and are often used as input parameters of the PBPK model to dynamically calculate solubility in the different segments of the GI tract and account for the influence of prandial state on the drug solubility, dissolution rate and permeation rate due to the concentration of bile salts assuming different diffusion for free and micelle-bound drug (Miller et al., 2011). Weak bases may be subject to precipitation in the high $\mathrm{pH}$ of the intestinal environment after dissolving in the low $\mathrm{pH}$ of stomach acid. The highly ionised state of acids in the intestinal lumen may increase solubility, but also hinder permeation through the phospholipid membranes of the intestinal wall. Acids and bases have the potential to distribute differently into tissues in the body, depending upon the tissue composition and their affinity for different phospholipids; in silico predictions of volume of distribution account for tissue composition and these differences between acids and bases (Rodgers and Rowland 2006). Lipophilicity may also affect dissolution in aqueous media, and highly lipophilic compounds can be subject to enhanced solubilisation by bile salts (Mithani et al., 1996), an area which has the potential for error within the PBPK framework, especially if solubility in biorelevant media are not measured experimentally.

The Biopharmaceutics Classification System (BCS), as a classic categorisation of compounds into high and low solubility and high and low permeability, has been used extensively to qualitatively predict in vivo oral drug behaviour. In contrast, PBPK has the potential to quantitatively describe the qualitative dynamics indicated by the BCS classification and this can be tested by comparing the predictive abilities of PBPK for the different classes of compounds. For example, for PBPK to be at least as successful as the BCS benchmark, it 
should be able to distinguish differences in bioavailability between high and low permeable compounds, and differences in relative bioavailability between high and low soluble compounds.

\section{Methods}

Inclusion criteria were employed in order to select APIs from the OrBiTo API database for the simulation exercise. The criteria were primarily based on the minimum set of parameters necessary to simulate a compound using the PBPK absorption model in the different software packages and included the availability of: molecular weight, $\operatorname{LogP} / \mathrm{D}$, fraction unbound in human plasma (fup), any clearance source scalable to human, in vitro permeability with reference compounds, at least one measure of solubility and available clinical data following per oral administration of the given drug. Of the 83 APIs in the OrBiTo database at the start of the exercise, 43 satisfied the inclusion criteria. For more details on the API selection process and comparison of the simulation set with the entire database, see companion paper (Margolskee et al. - Part 1 - Submitted).

A large scale evaluation of the predictive performance of existing in silico methods was undertaken. Three software packages, GastroPlus ${ }^{\mathrm{TM}}$ (Simulations Plus Inc., Lancaster, CA), Simcyp $^{\circledR}$ (Certara, Sheffield, UK) and GI-Sim (AstraZeneca, London, UK), were employed to produce bottom-up predictions for all of the 43 APIs in the simulation set. Each participating institution generated predictions for all available clinical study arms for the APIs that they had been allocated. A certain degree of overlap in API allocation was allowed to test for user differences. Limited standard operating procedures were provided for Simcyp and GI-Sim, however, most decisions on parameter data selection and simulation setup were left to the individual modellers at each institution. For more details on the procedure for performing the simulations see companion paper ( Margolskee et al. - Part 2 - Submitted). 
Predictive performance of the PBPK software packages was evaluated through comparison of typical pharmacokinetic (PK) parameters between simulated and observed values. These PK parameters were calculated as described in Part 2 (Margolskee et al. - Part 2 - Submitted). The presented PK parameters included: $\mathrm{AUC}_{0-\mathrm{t}, \text { last }}$ (area under the curve from time zero to last measured time point), $\mathrm{AUC}_{0-\mathrm{Inf}}$ (AUC from time zero extrapolated to time infinity), $\mathrm{C}_{\max }$ (maximum concentration in plasma), $\mathrm{t}_{\max }$ (time of peak concentration), $\mathrm{t}_{1 / 2}$ (terminal halflife), CL (clearance), CL/F (oral apparent CL), $\mathrm{V}_{\mathrm{d}}$ (volume of distribution), $\mathrm{V}_{\mathrm{d}} / \mathrm{F}$ (oral apparent $\mathrm{V}_{\mathrm{d}}$ ), MTT (mean transit time), MRT (mean residence time), $\mathrm{F}_{\text {oral }}$ (bioavailability), MAT (mean absorption time), $\mathrm{F}_{\text {rel }}$ (relative bioavailability), relative $\mathrm{C}_{\max }$, and relative AUC. Summary statistics for describing the overall performance of the simulations were decided upon through consensus between the involved institutions and calculated as specified in our companion paper ( Margolskee et al. - Part 2 - Submitted). Statistical metrics included: \% within two, three and ten-fold of observed, Average Fold Error (AFE), Absolute AFE (AAFE), Pearson regression coefficient (R) and Concordance Correlation Coefficient (CCC) (Lin, 1989; Poulin et al., 2011). The analysis presented in this manuscript focused on single dose and fasted state study arms only (excluding: multiple dose and fed state simulations).

\subsection{Grouping based on drug-specific properties}

APIs were separated based on drug-specific properties of interest to evaluate the potential impact on the performance of the models. Properties investigated include molecular weight (MW), acid/base nature, lipophilicity ( $\log \mathrm{P}$ and/or $\log \mathrm{D}), \mathrm{BP}, \mathrm{fu}_{\mathrm{p}}$, BCS class, dose number $\left(D_{o}\right)$ and estimated $f_{a}$ from scaled human effective permeability $\left(P_{\text {eff }}\right)$.

Groupings for acid/base nature included acid, ampholyte, neutral, weak base, and strong base categories, where strong bases had at least one pKa greater than 7 . For each of the properties $\mathrm{MW}, \log \mathrm{P}, \log \mathrm{D}, \mathrm{BP}$ and $\mathrm{fu}_{\mathrm{p}}$, the APIs were separated into four quartiles. Quartiles for each 
of these properties are displayed in Table 1 . The $\log \mathrm{D}$ values used in the groupings were the reported $\log \mathrm{D}$ values taken at the $\mathrm{pH}$ closest to 7.4 for each API. In the case for thirty five of the APIs this was $\mathrm{pH} 7.4$, while for the remaining eight APIs the closest $\mathrm{pH}$ ranged from 6.5 to 8 (Margolskee et al. - Part 1 - Submitted).

Grouping based on $D_{o}$ and $f_{a}$ followed the BCS cut-offs of $D_{o} \leq 1$ and $D_{o}>1$, and $f_{a}<0.9$ and $f_{a} \geq$ 0.9. Grouping based on BCS class was carried out according to the reported BCS class of the compounds in the database, or if this was not available, an estimated BCS classification was assigned from $\mathrm{f}_{\mathrm{a}}$ based on scaled human Peff, and dose number based on maximum reported dose and aqueous solubility. For further details of these calculations, see companion paper (Margolskee et al. - Part 1 - Submitted).

Table 1: Quartiles for each of the properties of $\mathrm{MW}, \log \mathrm{P}, \log \mathrm{D}, \mathrm{BP}$, and $\mathrm{fu}_{\mathrm{p}}$ for the simulated APIs

\begin{tabular}{|l|l|l|l|l|}
\hline & Q1 & Q2 & Q3 & Q4 \\
\hline MW & $(150,365 \mathrm{~g} / \mathrm{mol}]$ & $(365,440 \mathrm{~g} / \mathrm{mol}]$ & $(440,505 \mathrm{~g} / \mathrm{mol}]$ & $(505,870 \mathrm{~g} / \mathrm{mol}]$ \\
\hline $\log \mathbf{P}$ & $(-0.72,2.545]$ & $(2.545,3.3]$ & $(3.3,4.49]$ & $(4.49,7.75]$ \\
\hline $\log \mathbf{D}$ & $(-1.45,1.29]$ & $(1.29,2.55]$ & $(2.55,3.17]$ & $(3.17,5.8]$ \\
\hline $\mathbf{B P}$ & $(0.517,0.595]$ & $(0.595,0.640]$ & $(0.640,0.925]$ & $(0.925,3.300]$ \\
\hline $\mathbf{f u}_{\mathbf{p}}$ & $(0.0002,0.0125]$ & $(0.0125,0.05]$ & $(0.05,0.0855]$ & $(0.0855,0.74]$ \\
\hline
\end{tabular}

Geometric mean FEs were calculated for each API, averaging over API specific study arms (to account for APIs with different numbers of simulated study arms). APIs were categorised according to properties of interest, and summary statistics of the PK parameters were calculated for each group.

In order to test for interdependencies in the API parameters that may impact the interpretation of the results, Pearson correlation coefficients were calculated for each pairwise combination 
of relevant quantitative parameters. The parameters analysed were $\mathrm{MW}, \log \mathrm{P}, \log \mathrm{D}$, highest basic $\mathrm{pKa}$, lowest acidic $\mathrm{pKa}, \operatorname{logit}\left(\mathrm{fu}_{\mathrm{p}}\right), \log (\mathrm{BP}-0.5), \operatorname{logit}\left(\mathrm{f}_{\mathrm{a}}\right)$, and $\log \left(\mathrm{D}_{\mathrm{o}}\right)$, where $\operatorname{logit}(\mathrm{x})=$ $\log (\mathrm{x} /(1-\mathrm{x}))$. The transformations for $\mathrm{fu}_{\mathrm{p}}, \mathrm{BP}, \mathrm{f}_{\mathrm{a}}$ and $\mathrm{D}_{\mathrm{o}}$ were chosen so the transformed variables would be approximately normally distributed, allowing for more meaningful correlation estimates. Correlations greater than 0.7 in magnitude were considered strong, while correlations between 0.5 and 0.7 were considered moderate.

\section{Results and Discussion}

Inspection of correlations between API properties revealed a strong negative correlation between $\log \mathrm{P}$ and $\operatorname{logit}\left(\mathrm{fu}_{\mathrm{p}}\right)$ and a strong positive correlation between lowest acidic $\mathrm{pKa}$ and $\log (\mathrm{BP}-0.5)$ (Figure 1). Moderate positive correlations included $\log \mathrm{P}$ vs $\log \mathrm{D}, \log \mathrm{D}$ vs lowest acidic pKa, highest basic pKa vs $\log (\mathrm{BP}-0.5)$, and $\operatorname{logit}\left(\mathrm{fu}_{\mathrm{p}}\right)$ vs $\log (\mathrm{BP}-0.5)$. Moderate negative correlations included highest basic pKa vs $\log \left(\mathrm{D}_{\mathrm{o}}\right)$ and $\log \mathrm{P}$ vs $\log (\mathrm{BP}-$ 0.5). Several of these correlations are not surprising, such as $\log \mathrm{P}$ and $\log \mathrm{D}$ which both relate to lipophilicity, and $\mathrm{fu}_{\mathrm{p}}$ and $\mathrm{BP}$ which relate to plasma and blood binding properties. The high correlation between $\log \mathrm{P}$ and plasma protein binding has also been well documented (Yamazaki and Kanaoka, 2004). These correlations should be taken into consideration when interpreting the results of this exercise. 


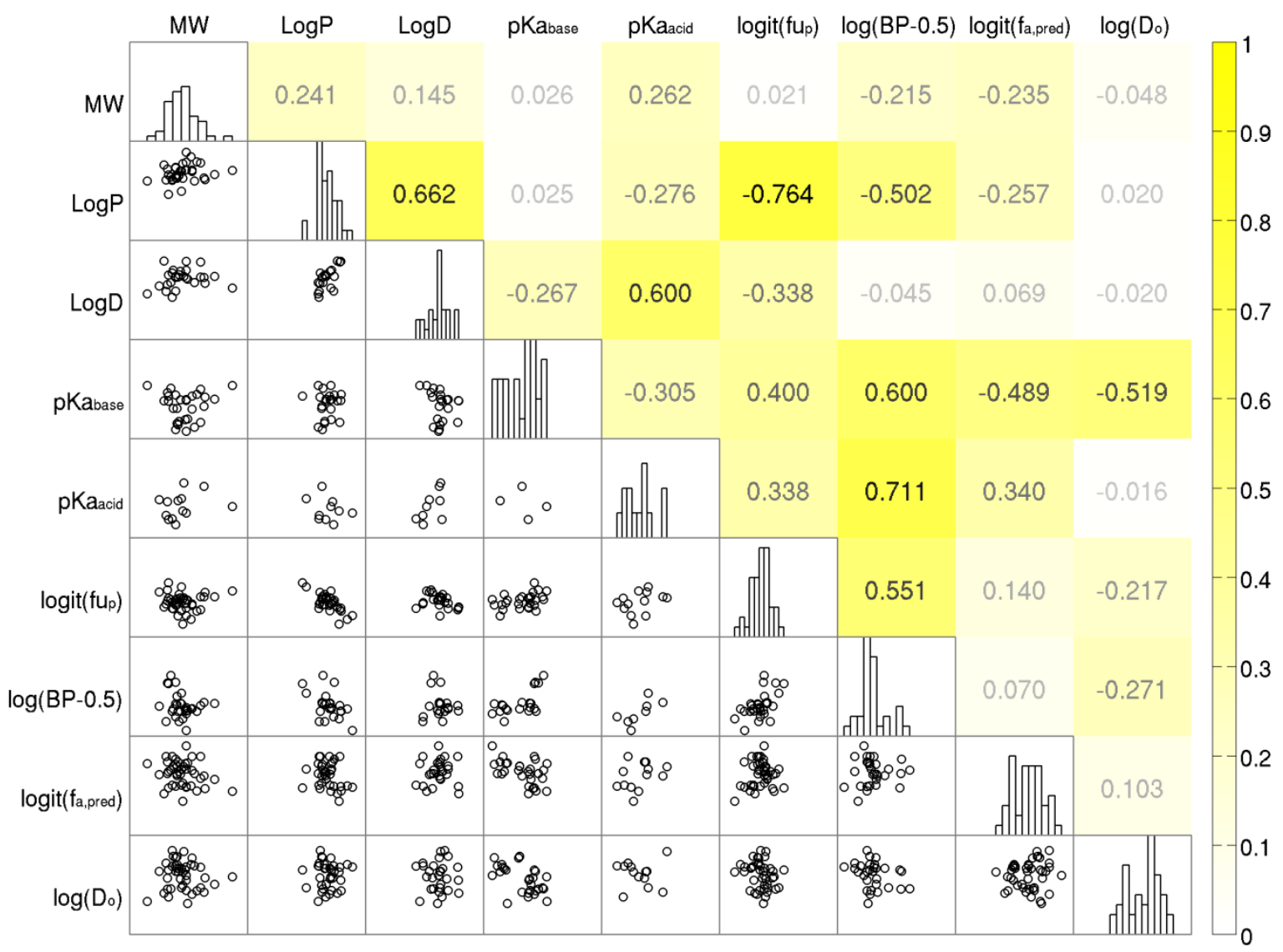

Figure 1: Pairwise comparison of API properties of interest detailing the Pearson correlation coefficients (above diagonal), pairwise scatterplots of property values (below diagonal), and individual histograms of property values (diagonal); $\mathrm{MW}=$ molecular weight, $\mathrm{pKa}_{\mathrm{base}}=$ highest basic $\mathrm{pKa}, \mathrm{pka}_{\mathrm{acid}}=$ lowest acidic $\mathrm{pKa}, \mathrm{fu}_{\mathrm{p}}=$ fraction unbound in plasma, $\mathrm{BP}=$ bloodto-plasma ratio, $\mathrm{f}_{\mathrm{a}, \text { pred }}=$ fraction absorbed predicted from in vitro Caco- 2 experiments, $\mathrm{D}_{\mathrm{o}}=$ dose number, $\operatorname{logit}(\mathrm{x})=\log (\mathrm{x} /(1-\mathrm{x}))$.

Sections 3.1-3.3 detail the influence of compound properties of interest on the predictive performance of different $\mathrm{PK}$ parameters including $\mathrm{AUC}_{0-\mathrm{t}, \text { last }}, \mathrm{F}_{\text {oral }}, \mathrm{F}_{\text {rel }}, \mathrm{C}_{\max }, \mathrm{CL}$ or CL/F and $\mathrm{V}_{\mathrm{d}}$ or $\mathrm{V}_{\mathrm{d}} / \mathrm{F}$. A summary of the findings is included in Table 2. Section 3.4 includes discussion around the interpretation of the results, and next steps. Analysis applied to the predictive performance of additional PK parameters can be found in the Supplementary Material. 
Table 2. Summary of impact of drug-specific properties on predictive performance

\begin{tabular}{|c|c|}
\hline \multicolumn{2}{|c|}{ Physicochemical properties } \\
\hline $\begin{array}{l}\text { Acid-base } \\
\text { nature }\end{array}$ & $\begin{array}{l}\text { Weak bases: Were poorly predicted where } \mathrm{F}_{\text {oral }} \text { was slightly overpredicted and } \\
\mathrm{F}_{\text {rel }} \text { was underpredicted. } \\
\text { Acids: Displayed negative bias for predicting } \mathrm{F}_{\text {oral }} \text {. }\end{array}$ \\
\hline $\log P$ & $\begin{array}{l}\text { Low LogP: APIs with low LogP gave better predictions of } \mathrm{F}_{\text {oral }} \text { compared to } \\
\text { compounds with higher LogP. } \\
\text { Midrange LogP: Gave better predictions of } \mathrm{F}_{\text {rel }} \text { compared to high and low } \\
\text { LogP. } \\
\text { Calculated LogP: Gave poor predictions compared to measured LogP. }\end{array}$ \\
\hline LogD & $\begin{array}{l}\text { Low LogD: Displayed better predictive performance of } \mathrm{F}_{\text {rel }} \text { compared to high } \\
\text { LogD. }\end{array}$ \\
\hline \multicolumn{2}{|c|}{ Plasma and blood binding } \\
\hline $\mathbf{F u} \mathbf{u}_{\mathbf{p}}$ & 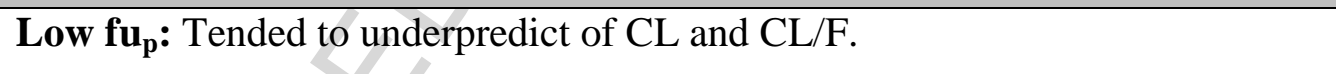 \\
\hline $\mathbf{B P}$ & High BP: Tended to give better predictive performance of CL and CL/F. \\
\hline \multicolumn{2}{|c|}{ BCS Classification } \\
\hline BCS Class & $\begin{array}{l}\text { BCS III and IV: } \text { Foral }_{\text {predictions displayed negative bias as compared with }} \\
\text { BCS I and II (highly permeable compounds). } \\
\text { BCS II and IV: } F_{\text {rel }} \text { predictions displayed negative bias as compared with } \\
\text { overprediction for BCS I and III (freely soluble compounds). }\end{array}$ \\
\hline $\mathbf{f}_{\mathbf{a}}$ & $\begin{array}{l}\mathbf{f}_{\mathbf{a}} \geq \mathbf{0 . 9} \text { : Displayed a lower bias, higher precision and better correlation metrics } \\
\text { for predictions of } F_{\text {oral }} \text { as compared to the } \mathrm{f}_{\mathrm{a}}<0.9 \text { group. }\end{array}$ \\
\hline $\mathbf{D}_{\mathbf{0}}$ & $\begin{array}{l}D_{\mathbf{o}}>1 \text { : Displayed an overall negative bias for predictions of } F_{\text {rel }} \text { and the } D_{0} \leq 1 \\
\text { group displayed an overall positive bias. }\end{array}$ \\
\hline \multicolumn{2}{|c|}{$\begin{array}{l}\mathrm{F}_{\text {oral }}=\text { Oral bioavailability, } \mathrm{F}_{\mathrm{rel}}=\text { Relative bioavailability between oral formulations, } \mathrm{fu}_{\mathrm{p}}= \\
\text { fraction unbound in plasma, } \mathrm{BP}=\text { Blood-to-plasma ratio, } \mathrm{BCS}=\text { Biopharmaceutics } \\
\text { Classification System, } \mathrm{f}_{\mathrm{a}}=\text { fraction absorbed as predicted from in vitro experiments, } \mathrm{D}_{\mathrm{o}}= \\
\text { dose number. }\end{array}$} \\
\hline
\end{tabular}




\subsection{Physicochemical properties}

The correlations between physico-chemical properties and the success in predictions were investigated for different parameters including acid/base nature and lipophilicity, while MW was also investigated, no trends were apparent.

\subsubsection{Acid-base Nature}

Predictions of oral $\mathrm{AUC}_{0-\mathrm{t}, \text { last }}$ for neutral compounds and strong bases generally performed well, displaying $80.0 \%$ and $92.3 \%$ of predictions within three-fold of observed data. Further, low variability was observed for FEs for neutral APIs and strong bases, with calculated AAFEs of 1.92 and 1.63, respectively. Reasonable correlations between predicted and observed were noted, where neutrals and strong bases displayed R coefficients of 0.89 and 0.93, and CCC of 0.34 and 0.93 (Figure 2A-C).

Poor predictions of $\mathrm{AUC}_{0-\mathrm{t}, \text { last }}$ were observed for acids with $10.0 \%$ and $20.0 \%$ within two and three-fold for p.o. simulations and a high variability with AAFE of 6.33 (Figure 2A-C). This poor predictive performance may be due to issues in predicting disposition, as both $\mathrm{F}_{\text {oral }}$ and $\mathrm{F}_{\text {rel }}$ between p.o. formulations and solutions were generally well predicted (80\% and $100 \%$ within two-fold) (Figure $2 \mathrm{D}, \mathrm{G})$. The $\mathrm{AUC}_{0-\mathrm{t} \text {,last }}$ predictions of p.o. simulations for acidic compounds displayed a low bias with AFE of 1.16 (Figure 2B), indicating the presence of both over- and underpredictions, while i.v. formulations displayed an overall overestimation as compared to observed data. This overprediction in i.v. exposure seems to be a combined underprediction of both CL (AFE of 0.346) and $V_{d}$ (AFE of 0.564) for acids (Table A5 and Table A6). 
A slight negative bias of $F_{\text {oral }}$ was observed for predictions of acids with an AFE of 0.580 (1.72-fold underprediction) and poor correlation ( $\mathrm{R}$ of -0.570 and $\mathrm{CCC}$ of -0.480 ). This could be related to a potential underestimation of permeability of acidic compounds, an overestimation of the impact of ionisation on permeation, or a lack of information on intestinal transporters. It could also be related to an underestimation of solubility of weak acids due to less than optimal intestinal model $\mathrm{pH}$ settings or an underestimation of contribution of bile micelles. However, it could also be due to a small number of poor predictions as the percent within two-fold was considered high at $80.0 \%$.

Poor predictions of $\mathrm{F}_{\text {oral }}$ were seen for weak bases (25.0\% within two-fold), showing a tendency towards overprediction (AFE 1.48), somewhat high source of variability (AAFE 2.46) and poor correlation between predicted and observed, with an R of -0.56 and CCC of 0.296 (Figure 2D-F). A slight overprediction of $\mathrm{F}_{\text {oral }}$ was observed, whereas $\mathrm{F}_{\text {rel }}$ between p.o. formulations and solution was underpredicted (Figure $2 \mathrm{H}$ ). This trend in predictions for weak bases may be due to insufficient data to inform precipitation of the formulation, as few APIs had information regarding precipitation in vitro (Margolskee et al. - Part 1 - Submitted).

$\mathrm{C}_{\max }$ was best predicted for neutral compounds, strong and weak bases with $60.0 \%, 53.8 \%$ and $45.5 \%$ predicted with two-fold of observed data, respectively. Neutral compounds and weak bases further displayed the strongest correlation metrics (R and CCC of 0.783 and 0.644, for weak bases; R and CCC of 0.922 and 0.749 for neutral APIs; Table A2). 

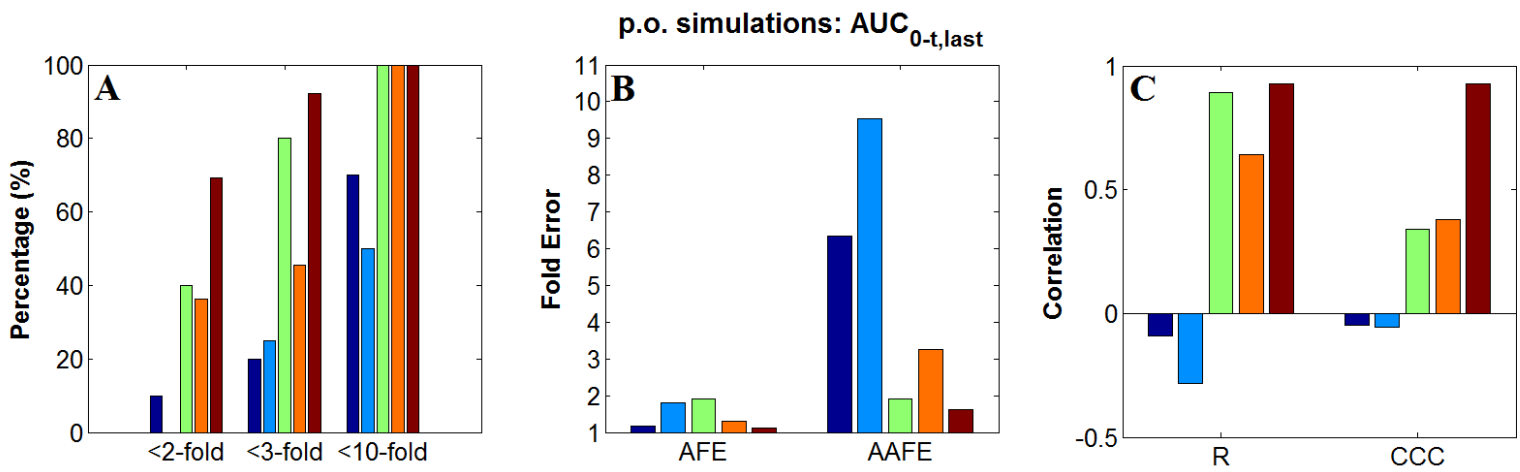

Acid $(n=10) \square$ Ampholyte $(n=4) \square$ Neutral $(n=5) \square$ Weak Base $(n=11) \square$ Strong Base $(n=13)$
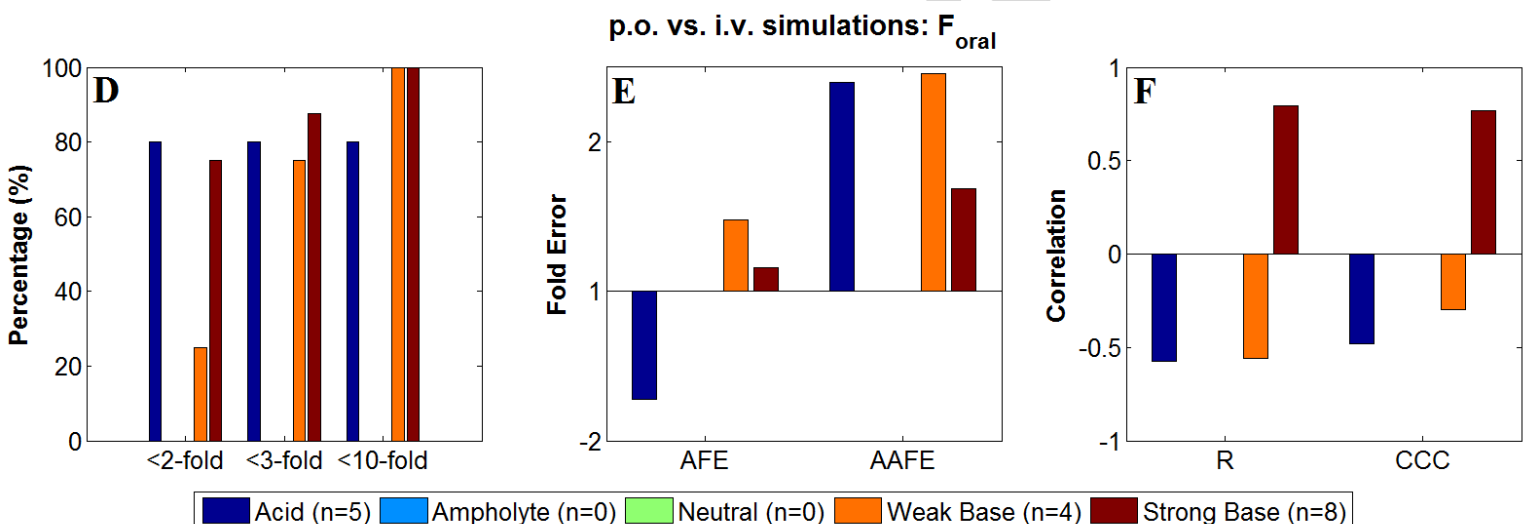

$\square$ Acid $(n=5) \square$ Ampholyte $(n=0) \square$ Neutral $(n=0) \square$ Weak Base $(n=4) \square$ Strong Base $(n=8)$

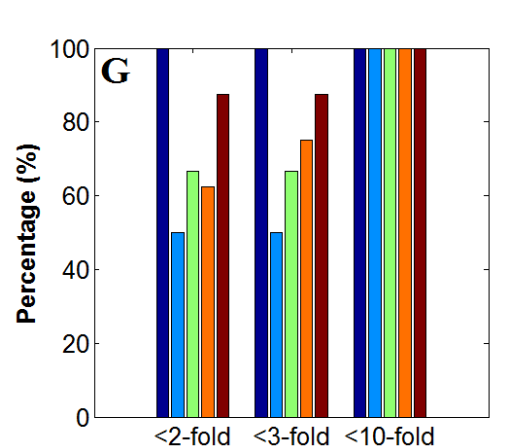

p.o. vs. solution simulations: $F_{\text {rel }}$
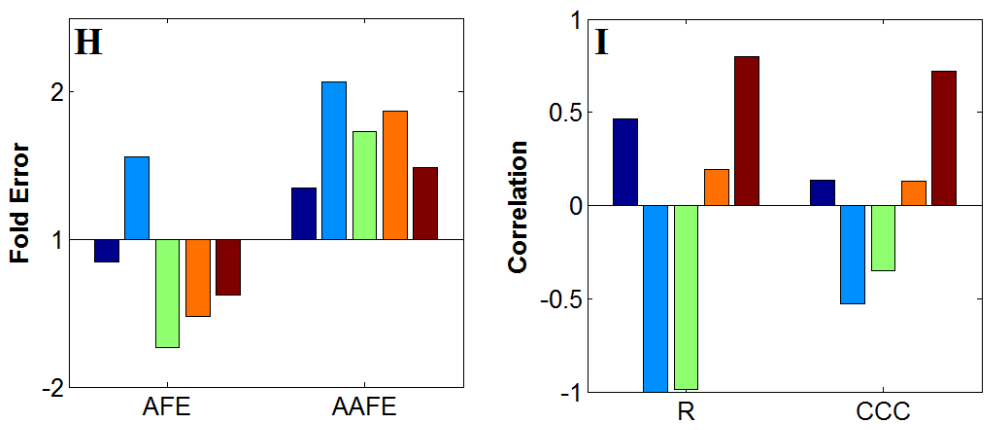

$\square$ Acid $(n=3) \square$ Ampholyte $(n=2) \square$ Neutral $(n=3) \square$ Weak Base $(n=8) \square$ Strong Base $(n=8)$

Figure 2. Prediction metrics for $\mathrm{AUC}_{0-\mathrm{t}, \text { last }}$ for p.o. formulations (A-C), Foral for p.o. vs. i.v. simulations (D-F), and Frel for p.o. vs. solution simulations (G-I), grouped by acid-base nature. 


\subsubsection{Lipophilicity}

\subsubsection{1. $\quad \log P$}

Investigating the impact of $\log \mathrm{P}$ on predictions of $\mathrm{AUC}_{0-\mathrm{t}, \text { last }}$ revealed predictions for APIs in the second quartile range of $\log \mathrm{P}(\mathrm{Q} 2: 2.545-3.3)$ to show a tendency towards better performance as compared to either extremes, with 55.6\% within two-fold error, AFE of 1.14, AAFE of 2.17, and R of 0.862 and CCC of 0.836 (Figure 3). Both $\operatorname{low} \log \mathrm{P}(\mathrm{Q} 1:-0.72-2.54)$ and high $\log \mathrm{P}(\mathrm{Q} 4:$ 4.49-7.75) APIs performed poorly compared to the Q2, displaying a lack of correlations, with an R of 0.0411 and 0.0489 for Q1 and Q4, respectively, and a CCC of 0.0183 and 0.0481 (Figure 3).

APIs in the upper quartile of $\log \mathrm{P}$ generally gave underpredictions of $\mathrm{F}_{\text {oral }}$ (AFE of 0.477 for Q4), while those in the third quartile gave overpredictions (AFE of 2.21). APIs with lower $\log \mathrm{P}$ gave the least biased predictions (AFE of 0.819 and 0.920 for Q1 and Q2, respectively). Predictions of $\mathrm{F}_{\text {oral }}$ for APIs with measured $\log \mathrm{P}$ were fairly consistent in their correlation with observed, with an R of 0.671, 0.464, and 0.588 for Q1, Q3, and Q4. APIs without measured $\log \mathrm{P}$ gave highly inconsistent predictions when comparing to observed data with an R of -1 (Figure 3D-F).

Relative AUC between p.o. formulations and solution was predicted best for APIs in the third quartile of $\log \mathrm{P}(\mathrm{Q} 3: 3.3-4.49)$, with $100 \%$ within two-fold $(\mathrm{n}=4)$, AFE of 1.06, low variability with AAFE of 1.19 , and strong correlation with R of 0.99 and CCC of 0.87 (Figure 3G-I). Relative AUC showed underpredictions on average for both APIs with low $\log \mathrm{P}(\mathrm{Q} 1)$ and high $\log \mathrm{P}(\mathrm{Q} 4)$ compared to APIs with middle range $\log \mathrm{P}(\mathrm{Q} 2$ and $\mathrm{Q} 3)$, displaying $\mathrm{AFE}$ 
of 0.57 and 0.54 (1.75 and 1.85-fold underpredictions) for Q1 and Q4, respectively, compared to 0.74 (1.35-fold underprediction) and 1.06, for Q2 and Q3 (Figure 3H). Underpredictions of $\mathrm{F}_{\text {rel }}$ for compounds with $\log \mathrm{P}$ values in $\mathrm{Q} 4$ suggest inadequate models for solubility and dissolution of highly lipophilic compounds, possibly underperforming bile enhancement models or lack of solubility data generated in biorelevant media for highly lipophilic compounds. Interestingly, Q4 showed high correlations between predicted and observed, with R of 0.985 , but relatively low CCC of 0.510 , suggesting the predictions were in the right direction but on the wrong scale (Figure 3I).

The average predictive performance for $\mathrm{V}_{\mathrm{d}}$ or $\mathrm{V}_{\mathrm{d}} / \mathrm{F}$ for i.v. and p.o. simulations was relatively unbiased for low $\log \mathrm{P}$ compounds with AFE ranging from 0.917 to 1.14 for Q1 through Q3, while a general trend of overprediction was observed for highly lipophilic compounds (AFE of 2.43 for Q4) (Figure 4 and Table A6). This may be related to the in silico methods utilised for predicting distribution into tissues, which varied between users and software. It is well known that in silico methods for predicting $\mathrm{V}_{\mathrm{ss}}$, such as the Poulin and Theil and Rodgers and Rowland model (Poulin and Theil, 2000; Rodgers et al., 2005; Rodgers and Rowland, 2006), overpredict the volume of distribution for highly lipophilic compounds. Alternative models have been developed to account for the overprediction in $\mathrm{V}_{\mathrm{ss}}$ for highly lipophilic compounds (Berezhkovskiy, 2004; Poulin and Haddad, 2012), and these were employed to some extent in the modelling of APIs for the OrBiTo simulation exercise at the modellers discretion. Further analysis will explore user differences such as this in an effort to test the performance of alternative methods. 

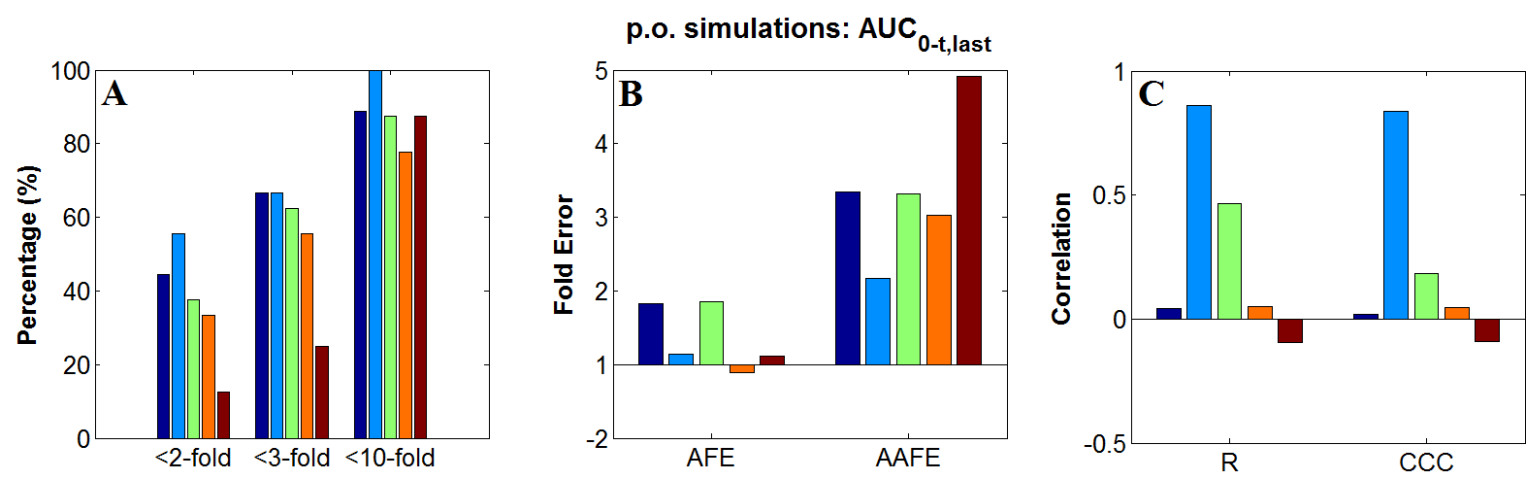

Q1: $(-0.72,2.545](n=9) \square$ Q2: $(2.545,3.3](n=9) \square$ Q3: $(3.3,4.49](n=8) \square \square$ Q4: $(4.49,7.75](n=9)$

Not Given $(\mathrm{n}=8)$
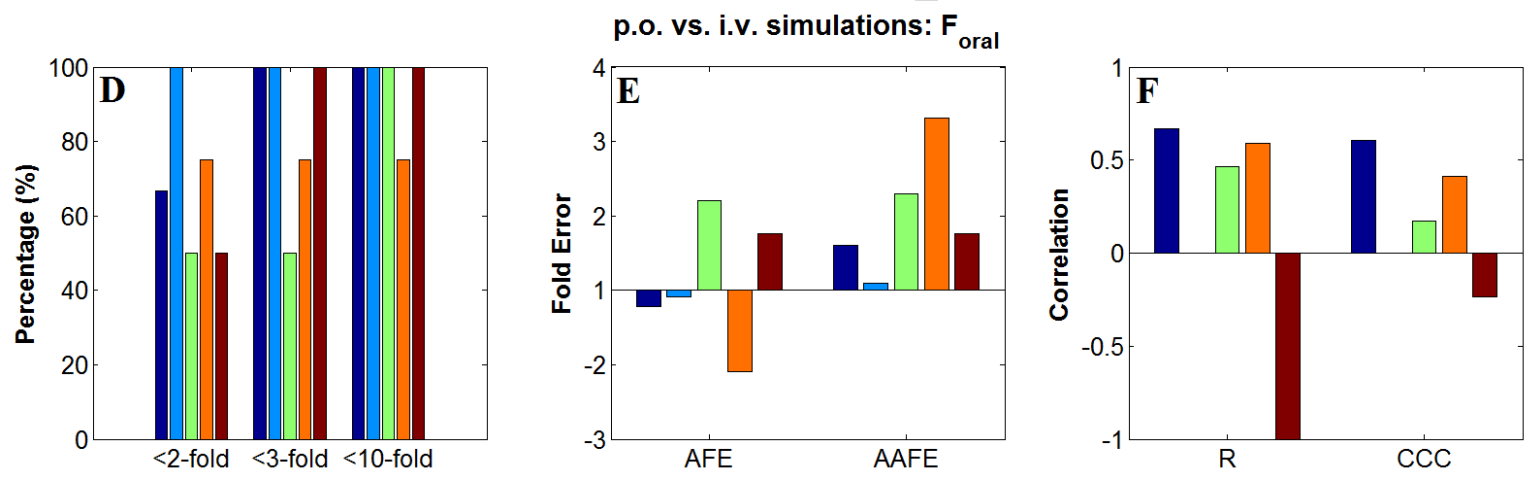

Q1: $(-0.72,2.545](n=6) \square Q 2:(2.545,3.3](n=1)$

Q3: $(3.3,4.49](n=4)$

Q4: $(4.49,7.75](n=4)$

Not Given $(n=2)$

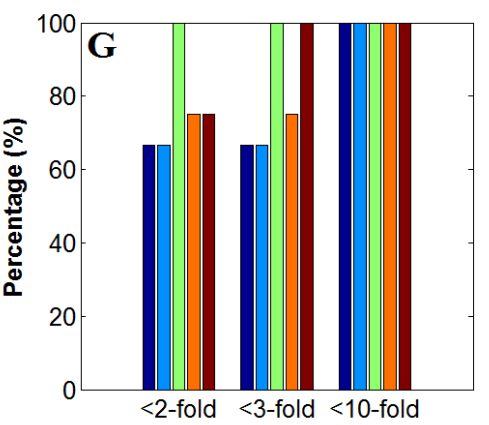

p.o. vs. solution simulations: $F_{\text {rel }}$
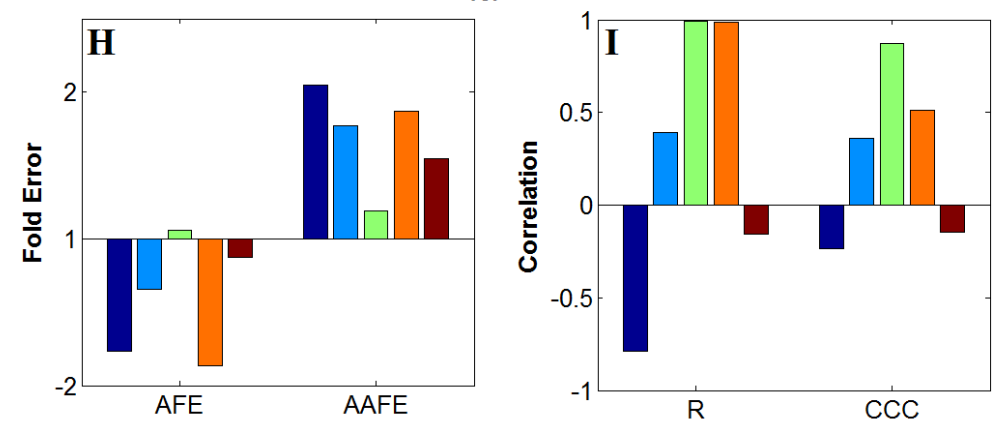

Q1: $(-0.72,2.545](n=3) \square$ Q2: $(2.545,3.3](n=9) \square$ Q3: $(3.3,4.49](n=4)$

Q4: $(4.49,7.75](n=4)$

Not Given $(n=4)$

Figure 3: Prediction performance measures of $\mathrm{AUC}_{0 \text {-t,last }}$ for p.o. formulations $(\mathrm{A}-\mathrm{C}), \mathrm{F}_{\text {oral }}$ for p.o. vs. i.v. simulations (D-F), and Frel for p.o. vs. solution simulations (G-I), grouped by quartiles of $\log \mathrm{P}$. 


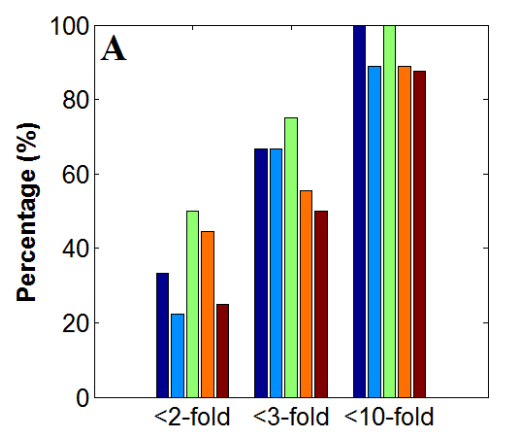

p.o. and i.v. simulations: Vd or Vd/F
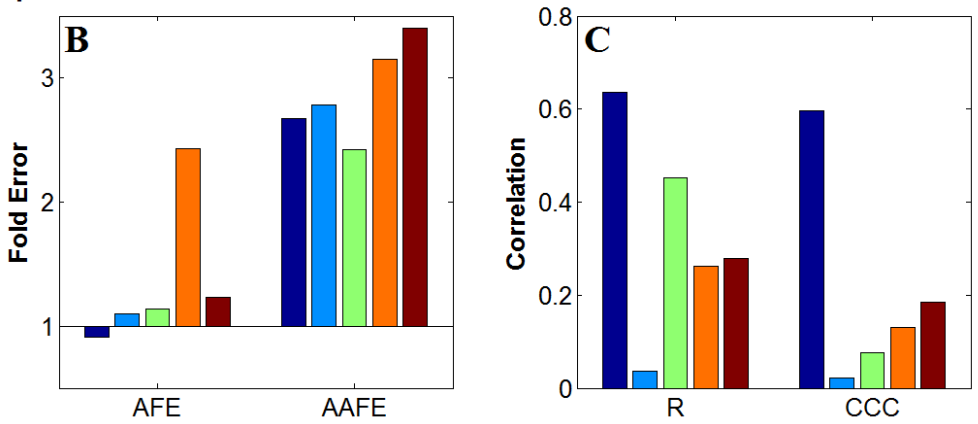

Q1: $(-0.72,2.545](n=9) \square$ Q2: $(2.545,3.3](n=9) \square$ Q3: $(3.3,4.49](n=8) \square$ Q4: $(4.49,7.75](n=9)$

Not Given $(\mathrm{n}=8)$

Figure 4. Prediction metrics of volume of distribution $\left(\mathrm{V}_{\mathrm{d}}\right)$ for i.v. formulations or oral apparent $\mathrm{V}_{\mathrm{d}}\left(\mathrm{V}_{\mathrm{d}} / \mathrm{F}\right)$ for p.o. formulations, grouped by $\log \mathrm{P}$ quartiles.

\subsubsection{2. $\quad \log D$}

Prediction performance of $\mathrm{AUC}_{0-\text { t, last }}$ for p.o. simulations for APIs in the first quartile of $\log \mathrm{D}$ (Q1: $-1.45-1.29, \mathrm{n}=7$ ) was poor, with $14.3 \%, 28.6 \%$ and $57.1 \%$ within two, three and ten-fold error, vs. 33.4\%, 52.3\%, and 90.7\%, for the APIs in Q2-Q4 combined (Figure 5). AUC -t,last $_{\text {lat }}$ was overpredicted on average for APIs in Q1, with AFE of 2.19 vs. 1.15 for Q2-Q4 combined. Further, Q1 showed high variability with AAFE of 7.60 vs. 3.29 for Q2-Q4, and low correlation between predicted and observed with R of -0.239 and CCC of -0.083 (Figure $5)$.

Predictions for $\mathrm{AUC}_{0-\mathrm{t}, \mathrm{last}} \mathrm{F}_{\text {oral }}$ were poor for APIs in Q1 of $\log \mathrm{D}$, displaying AFE of 0.418 (or 2.38-fold underprediction; $\mathrm{n}=3$; vs. AFE of 1.14 for Q2-Q4; $\mathrm{n}=9$ ), high variability with AAFE of 4.17 (vs. 1.87 for Q2-Q4), and poor correlation between predicted and observed with R of -0.855 and CCC of -0.706 . However, more APIs in Q1 had predictions of $\mathrm{F}_{\text {oral }}$ within two-fold compared with Q2-Q4 (66.7\% vs. 55.6\%), and less within three and ten-fold, 
$66.7 \%$ and $66.7 \%$, vs. $88.9 \%$ and $100 \%$, for Q2-Q4, indicating the results may be skewed by a single outlier (Figure 5D-F).

Predictions for $\mathrm{F}_{\text {rel }}$ between p.o. and solutions seemed to perform better for lower quartiles of $\log$, with 100\% within two-fold for Q1, 75.0\% for each of Q2 and Q3, and 50.0\% for Q4.

On average, the bias for the different quartiles appeared comparable, with AFE of 0.868 , $0.829,1.09$, and 0.606 for Q1, Q2, Q3, and Q4, respectively. The variability in the predictions appeared to increase with increasing $\log \mathrm{D}$, with AAFE of 1.35, 1.70, 1.66, and 1.88 for Q1, Q2, Q3 and Q4. Additionally, correlation between predicted and observed $\mathrm{F}_{\text {rel }}$ declined with increasing $\log \mathrm{D}(\mathrm{R}$ of $0.466,0.136,0.0683$ and -0.392 and $\mathrm{CCC}$ of 0.136 , 0.125, 0.0662, and -0.179 for Q1, Q2, Q3, and Q4; Figure 5G-I). 

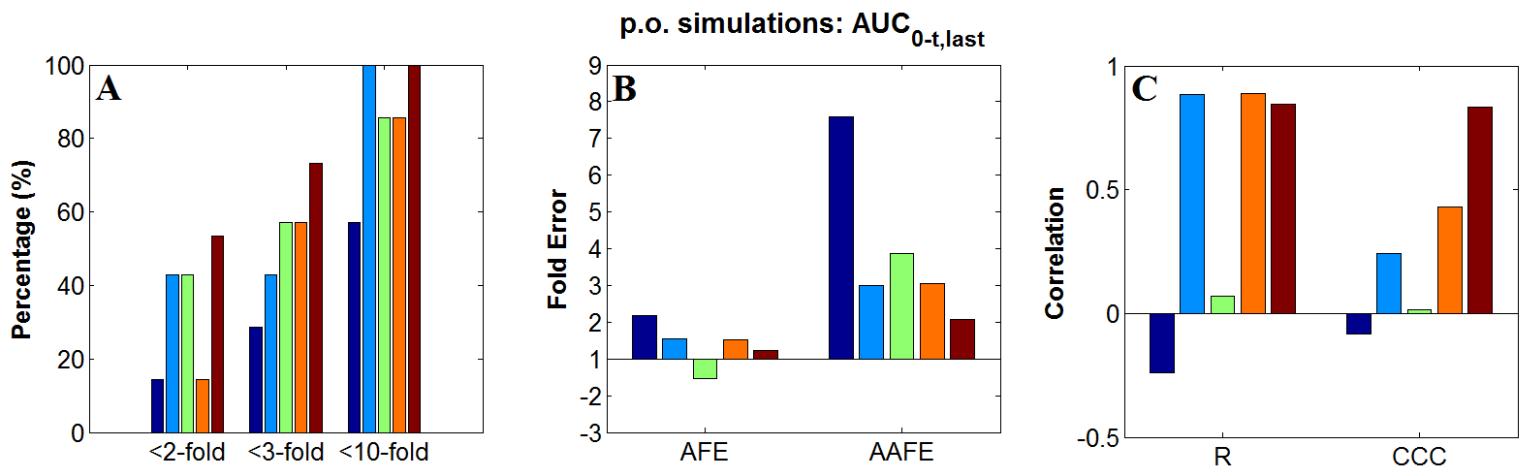

Q1: $(-1.45,1.29](n=7) \square$ Q2: $(1.29,2.55](n=7) \square$ Q3: $(2.55,3.17](n=7) \square$ Q4: $(3.17,5.8](n=7) \square$ Not Given $(n=15)$

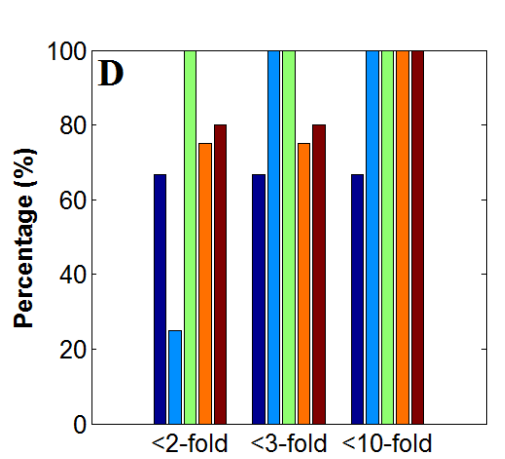

p.o. vs. i.v. simulations: $F_{\text {oral }}$
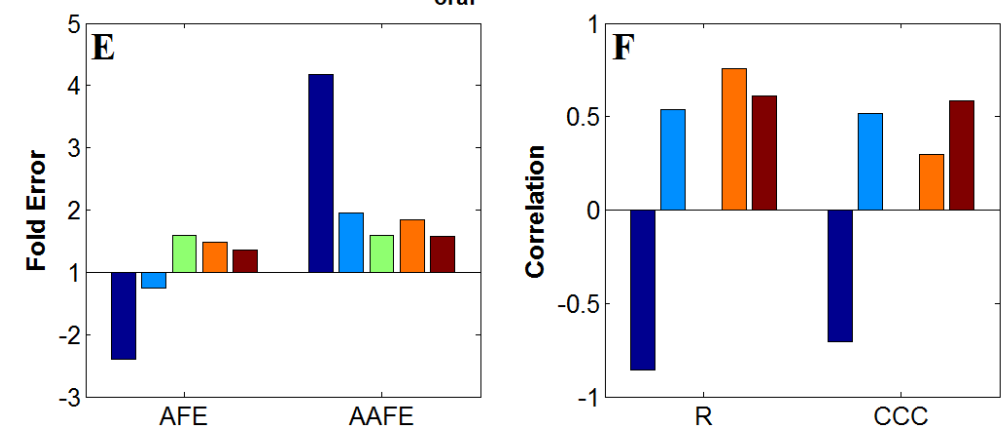

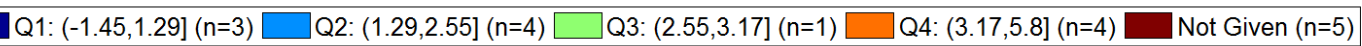

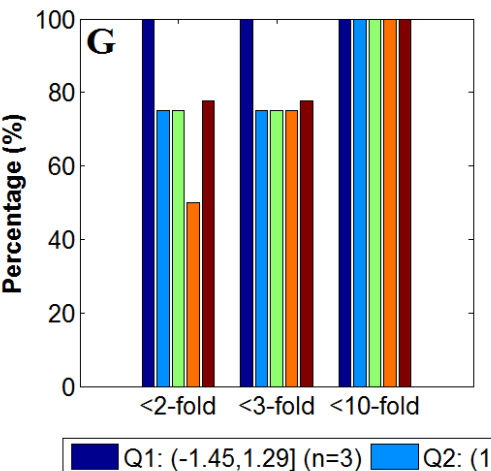

p.o. vs. solution simulations: $F_{\text {rel }}$

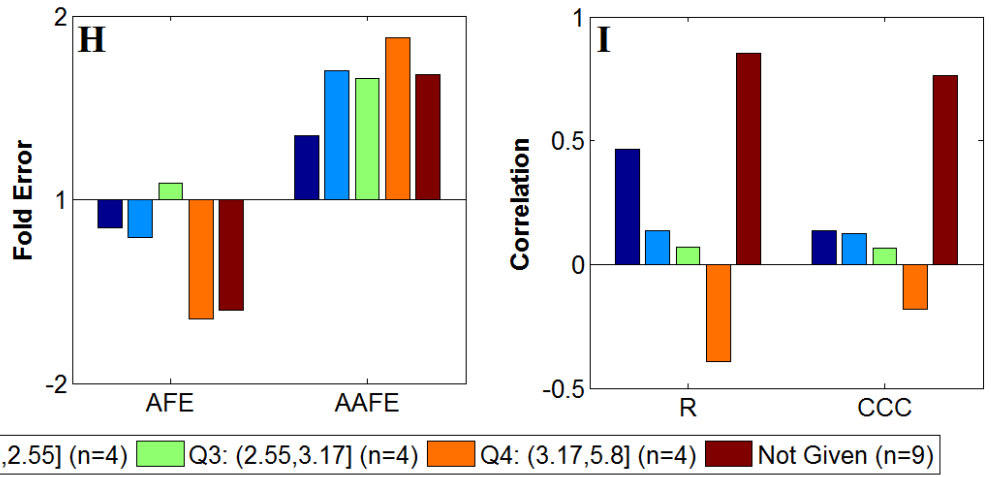

Figure 5: Prediction performance of $\mathrm{AUC}_{0-\mathrm{t}, \text { last }}$ for p.o. formulations (A-C), Foral for p.o. vs. i.v. simulations (D-F), and Frel for p.o. vs. solution simulations (G-I), grouped by $\log \mathrm{D}$ quartiles.

Predictions of p.o. $\mathrm{AUC}_{0-\mathrm{t}, \text { last }}$ performed poorly for $\mathrm{APIs}$ for which $\log \mathrm{P}$ was not given $(\mathrm{n}=8)$ compared to those for which $\log P$ was reported $(n=35)$. While the overall average performance of the APIs without $\log \mathrm{P}$ was very good at predicting $\mathrm{AUC}_{0-\mathrm{t}, \text { last }}(\mathrm{AFE}$ of 1.11), 
the variability was high, with an AAFE of 4.91 (vs. 2.90 for APIs providing logP) and $12.5 \%$ fell within 2 fold (vs. 42.9\%), and additionally, there was poor correlation between predicted and observed $\mathrm{AUC}_{0-\mathrm{t}, \text { last }}$ with $\mathrm{R}$ of -0.0936 and $\mathrm{CCC}$ of -0.0913 (Figure 3). In contrast, the group of APIs for which $\log \mathrm{D}$ was not reported performed very well in predicting $\mathrm{AUC}_{0-\mathrm{t}, \mathrm{last}}$, with $53.3 \%$ and $73.3 \%$ within two and three-fold error, vs. $28.7 \%$ and $46.4 \%$, for APIs where $\log \mathrm{D}$ was provided (Q1-Q4 combined). APIs not reporting $\log \mathrm{D}$ also had relatively unbiased estimates and reasonable variability compared with APIs reporting $\log \mathrm{D}$. Correlation between predicted and observed was also very high with R of 0.846 and CCC of 0.834 (Figure 5).

\subsection{Plasma and blood binding values}

In this section, the connection between blood and plasma binding properties and prediction performance was investigated for different pharmacokinetic parameters. Summary statistics were investigated for APIs divided into BP quartiles, and divided into fu $\mathrm{p}_{\mathrm{p}}$ quartiles (Table 1).

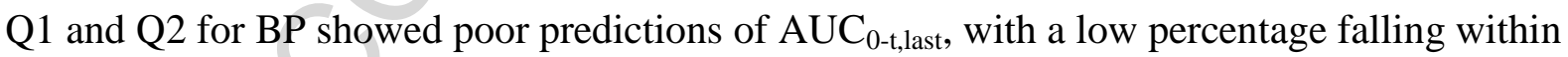
n-fold, high variability, and poor correlations between predicted and observed (Figure 6). Clearance predictions also showed high variability and poor correlation for lower values of BP (Figure 6D-F, and Table A5). A similar trend was seen for fu $\mathrm{p}_{\mathrm{p}}$, where Q1 and Q2 generally underperformed compared with Q3 and Q4 with low correlations between predicted and observed (Figure 7C). There was a moderate correlation between fu $\mathrm{p}_{\mathrm{p}}$ and $\mathrm{BP}$ for our dataset (Figure 1), and a great overlap between APIs of the lowest BP quartiles and the lowest $\mathrm{fu}_{\mathrm{p}}$ group $\left(\mathrm{fu}_{\mathrm{p}}<0.01\right)$. Low BP indicates lack of uptake into red blood cells, which may reflect the high plasma protein binding in these cases. The underestimations of clearance observed for lower $\mathrm{fu}_{\mathrm{p}}$ (highly protein bound) compounds could be explained by unknown 
mechanisms for the transfer of highly lipophilic drugs into cells from proteins, as a modest positive relationship between $\log \mathrm{P}$ and percent bound to protein in plasma (or negative relationship between $\log \mathrm{P}$ and $\mathrm{fu}_{\mathrm{p}}$ ) has been documented in the literature (Yamazaki and Kanaoka, 2004), similarly a strong correlation was observed between $\log \mathrm{P}$ and $\mathrm{fu}_{\mathrm{p}}$ for our dataset (Figure 1).

De Buck 2007 investigated the prediction of hepatic clearance using two different methods, method 1 using the traditional formula involving $\mathrm{fu}_{\mathrm{p}} / \mathrm{BP}$ and $\mathrm{fu}_{\mathrm{inc}}$, and method 2 where the effects of $\mathrm{fu}_{\mathrm{p}} / \mathrm{BP}$ and $\mathrm{fu}_{\mathrm{inc}}$ were assumed to cancel each other out. The second method performed considerably better at predicting in vivo hepatic clearance from in vitro $\mathrm{CL}_{\mathrm{int}}$, potentially through unintentionally compensating for the inherent underprediction in CLint when scaling from HLMs or human hepatocytes (Hallifax et al., 2012). The results of De Buck 2007 and the relationship we have observed here between low BP and high variability, and low $\mathrm{fu}_{\mathrm{p}}$ and high variability in the prediction of clearance may be related.

\subsubsection{Blood to plasma ratio (BP)}

Simulated APIs were divided into four quartiles (Q1 to Q4; Table 1) based on average simulated blood-to-plasma ratios (BPs). The percent within n-fold increased with increasing BP quartile, where 0.00, 33.3, 50.0 and 63.6\% fell within two-fold for Q1 through Q4, respectively, 27.3, 44.4, 66.7 and $81.8 \%$ within three-fold, and 72.7, 77.8, 100, and 100\% within ten-fold. Similarly, the quartiles showed increasing precision with increasing BP with AAFE of 5.91, 4.46, 2.12, and 2.09 for Q1 through Q4. While Q1 showed a relatively low bias with AFE of $0.951, \mathrm{Q} 2$ through $\mathrm{Q} 4$ continued the trend of better performance with increasing BP, with AFE of 2.13, 1.57, and 0.98. Q1 and Q2 also showed poor correlation 
between predicted and observed with R of 0.0147 and -0.112 and CCC of 0.0136 and -0.101 . In contrast, Q3 and Q4 displayed good correlation between predicted and observed data with $\mathrm{R}$ of 0.825 and 0.921 and $\mathrm{CCC}$ of 0.727 and 0.908 (Figure 6A-C).

When examining the prediction of $\mathrm{CL}$ and $\mathrm{CL} / \mathrm{F}$ for p.o. and i.v. simulations, there was a tendency of better performance for the higher quartiles of BP. Q1 displayed 0.00, 18.2 and 81.8\% of predictions within two, three and ten-fold with similar results for Q2. Q3 and Q4 showed higher frequency within n-fold, with 50.0, 58.3 and 100\% for Q3, and 63.6, 81.8, and 100\% for Q4 falling within two, three and ten-fold. Q2 displayed the largest bias (AFE: 0.298, or a 3.36-fold underprediction) and poorest precision (AAFE: 7.00), whereas Q1 displayed the lowest AFE at 1.02 and Q4 the lowest AAFE at 2.05. Correlations between predicted and observed CL or CL/F progressively improved with increasing BP quartiles (R: 0.197, 0.189, 0.537, 0.793 for Q1 through Q4 and CCC: 0.0464, 0.123, 0.243, 0.790 for Q1 through Q4; Figure 6D-F, and Table A5).

Investigating the impact of $\mathrm{BP}$ on the performance of predicting $\mathrm{C}_{\max }$ revealed an overall trend of improvement towards compounds with higher $\mathrm{BP}$, for instance $\mathrm{CCC}$ ranged from 0.224 for Q1 to 0.636 for Q4. Similarly, improvements were seen in the bias (AFE Q1-Q4: 0.247-0.75) and precision (AAFE Q1-Q4: 7.36-2.73) with increasing BP (Table A2). 

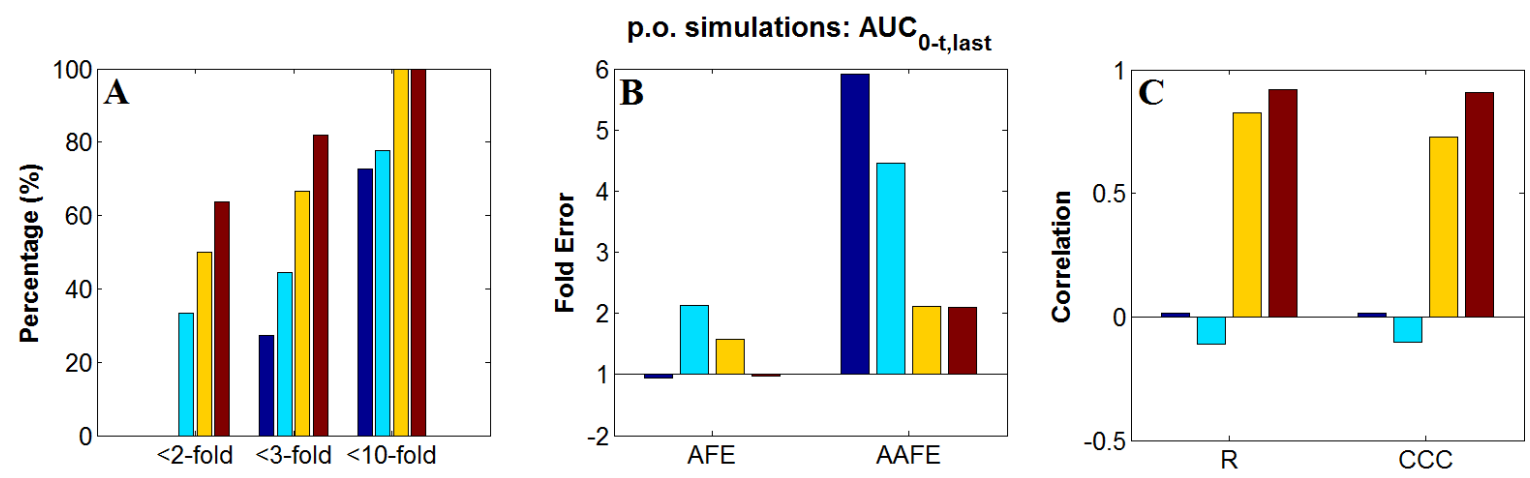

Q1: $(0.517,0.595](n=11) \square$ Q2: $(0.595,0.640](n=9) \square$ Q3: $(0.640,0.925](n=12)$

Q4: $(0.925,3.300](n=11)$

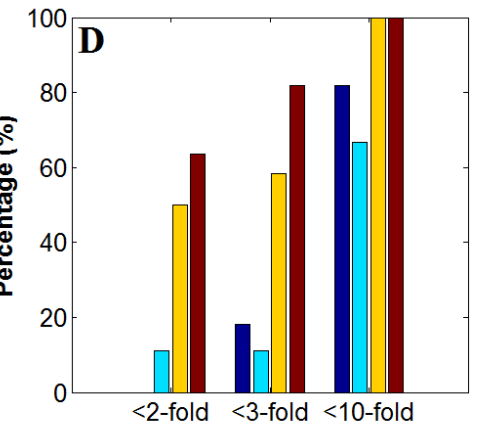

p.o. and i.v. simulations: $C L$ or CL/F
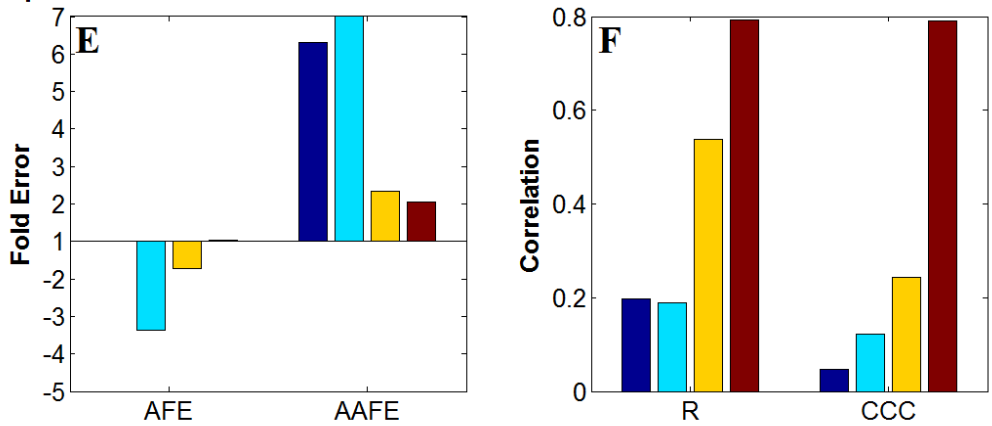

Q1: $(0.517,0.595](n=11)$

Q2: $(0.595,0.640](n=9) \square$ Q3: $(0.640,0.925](n=12)$

Q4: $(0.925,3.300](n=11)$

Figure 6: Prediction metrics for $\mathrm{AUC}_{0-\mathrm{t}, \text { last }}$ for p.o. formulations (A-C) and $\mathrm{CL}$ or $\mathrm{CL} / \mathrm{F}$ for i.v. and p.o. simulations (D-F) as compared to blood-to-plasma ratio value as divided into the $1^{\text {st }}$ to $4^{\text {th }}$ quartile $(\mathrm{Q} 1-4)$.

\subsubsection{Fraction unbound in plasma $\left(f u_{p}\right)$}

Examining the predictive performance of simulated p.o. $\mathrm{AUC}_{0-\mathrm{t}, \text { last }}$ in relation to simulated average $\mathrm{fu}_{\mathrm{p}}$ neglected to show any apparent trends. However, there was an increase in performance in terms of $\mathrm{R}$ and CCC with increasing percentiles, with $\mathrm{R}$ values of -0.0658 , $0.00985,0.527$, and 0.866 for Q1 through Q4, and CCC of $-0.0614,0.00851,0.400$, and 0.810 for Q1 through Q4, respectively (Figure 7). 

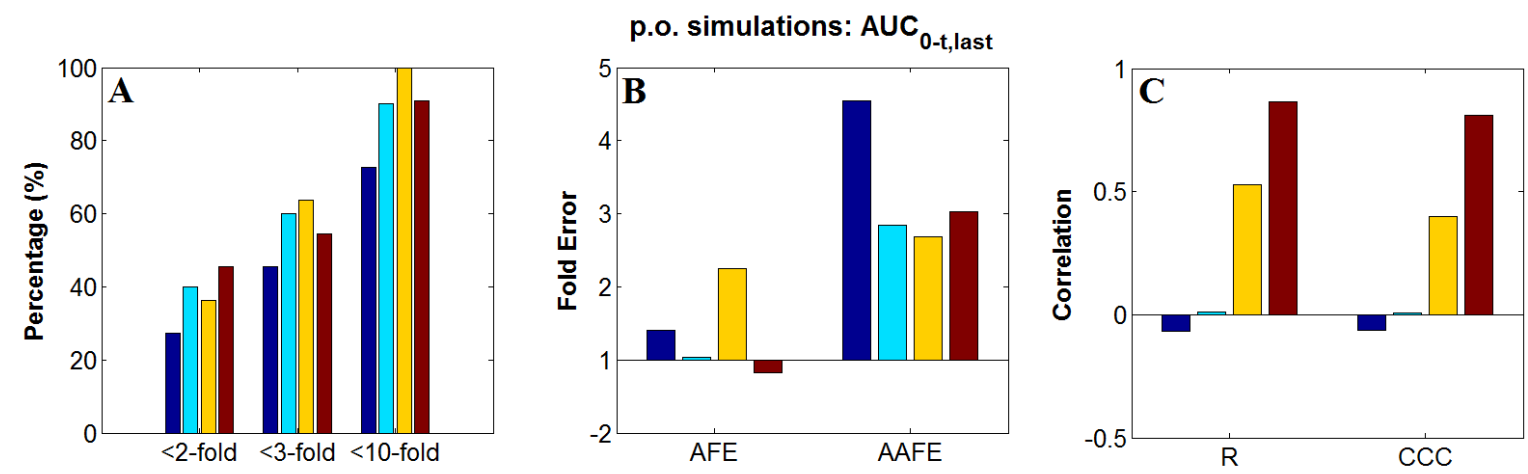

Q1: $(0.0002,0.0125](n=11) \square$ Q2: $(0.0125,0.05](n=10) \square$ Q3: $(0.05,0.0855](n=11)$

Q4: $(0.0855,0.74](n=11)$

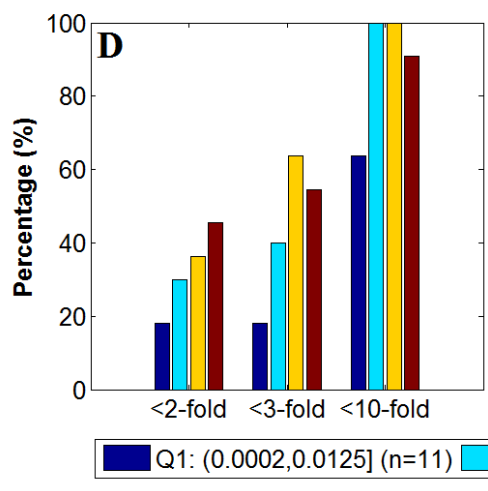

p.o. and i.v. simulations: CL or CL/F
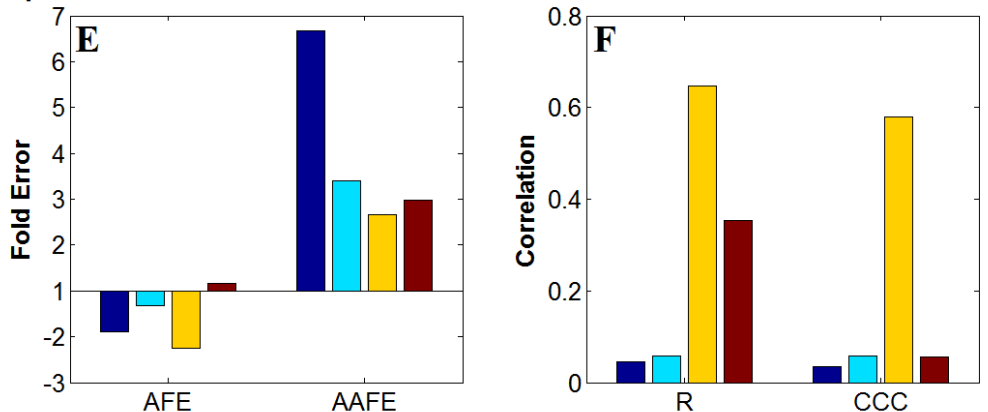

Q2: $(0.0125,0.05](\mathrm{n}=10) \square$ Q3: $(0.05,0.0855](\mathrm{n}=11)$

Q4: $(0.0855,0.74](n=11)$

Figure 7: Prediction metrics for $\mathrm{AUC}_{0-\mathrm{t}, \text { last }}$ for p.o. formulations $(\mathrm{A}-\mathrm{C})$ and $\mathrm{CL}$ or $\mathrm{CL} / \mathrm{F}$ for i.v. and p.o. simulations (D-F) as compared to as compared to fu $\mathrm{u}_{\mathrm{p}}$ value as divided into the $1^{\text {st }}$ to $4^{\text {th }}$ quartile (Q1-4).

\subsection{BCS Classification}

For BCS class I compounds, $37.5 \%$ of APIs displayed a predicted average oral $\mathrm{AUC}_{0-\mathrm{t}, \text { last }}$ within two-fold, with $87.5 \%$ of predictions falling within ten-fold, BCS class II compound displayed a similar level of percentage within two, three and ten-fold. BCS IV APIs displayed a lower degree of predictability with $33.33 \%$ falling within two-fold and $77.8 \%$ within tenfold; whereas analysis of BCS class III was limited to two APIs and could therefore be considered undetermined (Figure 5A). BCS class I, II and IV displayed a low AFE, 0.796, 1.55, and 1.47, respectively, and AAFE increased with increasing BCS class, 2.81, 3.30 and 
4.00 (Figure 5B). With respect to correlation parameters, BCS class I compounds outperformed the remaining classes, displaying an R value of 0.850 and a CCC value of 0.837 (Figure 8).

$\mathrm{F}_{\text {oral }}$ predictions for BCS classes III and IV (low permeable compounds) displayed negative bias as compared with BCS I and II (high permeable compounds), displaying AFE of 0.357 for BCS III and IV combined ( $\mathrm{n}=5)$ and 1.54 for BCS I and II combined (n=12; Figure 8E). Similarly, $\mathrm{F}_{\text {oral }}$ predictions for estimated $\mathrm{f}_{\mathrm{a}}<0.9$ displayed negative bias with AFE of 0.499 $(n=6)$ vs. 1.47 for APIs with estimated $f_{a} \geq 0.9$ (Figure 9E). This underprediction of $F_{\text {oral }}$ for low permeable compounds could potentially indicate an oversensitivity of the models to in vitro permeability measurements, improper intestinal surface area estimates, underestimates of colonic absorption and/or lack of intestinal transporter information. Simulations for highly permeable compounds $\left(f_{a} \geq 0.9\right)$ in general performed better than those for low permeable compounds in terms of predictions of p.o. $\mathrm{AUC}_{0-\mathrm{t}, \mathrm{last}}, \mathrm{C}_{\max }$ and $\mathrm{F}_{\text {oral. }}$. This is possibly not surprising, as for highly permeable compounds $\mathrm{f}_{\mathrm{a}}$ will saturate at a value close to1.0, thus providing limited information on prediction performance of the model. Looking at lower permeable compounds gives a better indication of the (lack of) precision and accuracy of scaling and modelling of permeability.

$\mathrm{F}_{\text {rel }}$ predictions for BCS classes II and IV (low soluble compounds) displayed negative bias, with AFE of 0.677 (a 1.48-fold underprediction) as compared with 1.20 overprediction for BCS I and III (high soluble compounds) (Figure 5H). Similarly, compounds with $\mathrm{D}_{\mathrm{o}}>1$ $(\mathrm{n}=21)$ displayed AFE of 0.681 vs. 1.38 for compounds with $\mathrm{D}_{\mathrm{o}} \leq 1$ (Figure $\left.10 \mathrm{E}\right)$. While the number of $\mathrm{F}_{\text {rel }}$ predictions for compounds in the higher soluble category was small (4 based 
on reported $\mathrm{BCS}$ and 3 based on calculated $\mathrm{D}_{\mathrm{o}}$ ), the underpredictions of $\mathrm{F}_{\text {rel }}$ for low soluble compounds suggest over sensitivity of the dissolution models to aqueous solubility. However, this could also be due to a lack of available measurements of solubility in biorelevant media, as $72.1 \%$ of the simulation set were missing this data (Margolskee et al. - Part 1 - Submitted).
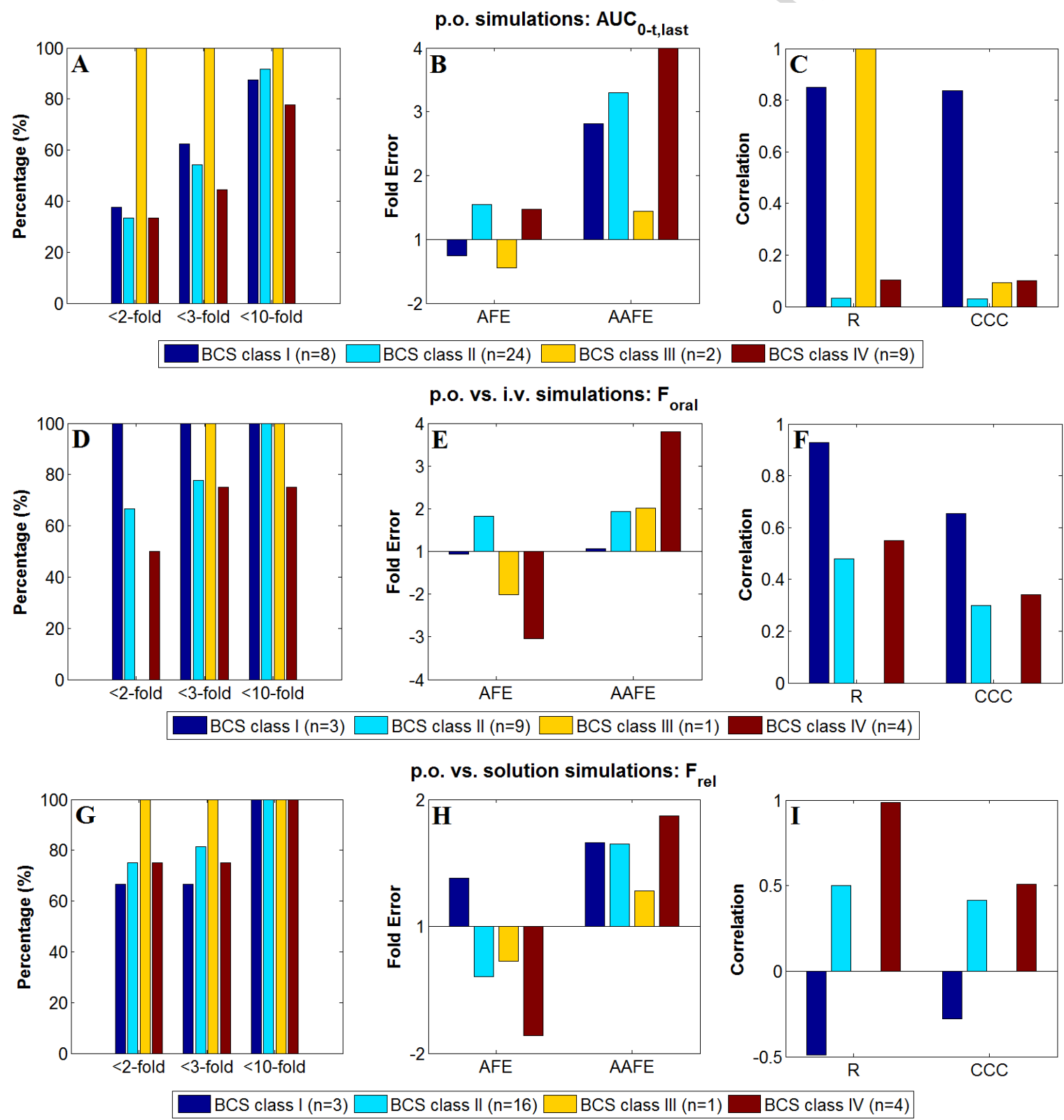

Figure 8: Statistical metrics of prediction success of oral $\mathrm{AUC}_{0-\mathrm{t}, \text { last }}$ for p.o. formulations (AC), $F_{\text {oral }}$ for p.o. vs. i.v. simulations (D-F), and $F_{\text {rel }}$ for p.o. vs. solution simulations (G-I), as compared to the biopharmaceutics classification system (BCS) classes I-IV. 


\subsubsection{Estimated fraction absorbed from in vitro permeability assay}

Permeability-limited APIs $\left(f_{\mathrm{a}}<0.9\right)$ displayed an improved prediction of p.o. $\mathrm{AUC}_{0-\mathrm{t}, \text { last }}$ as compared to highly permeable APIs $\left(f_{a} \geq 0.9\right)$ with regards to within two-fold with calculated values of 46.7 and $32.1 \%$, respectively; whereas highly permeable compounds displayed a higher frequency within ten-fold as compared to permeability limited APIs with 96.4 and 73.3\% (Figure 9A). Oral predictions of AUC for highly permeable APIs displayed slightly higher accuracy and precision compared to permeability-limited APIs with AFEs of 1.22 and 1.47, AAFEs of 3.08 and 3.47 (Figure 9B). Further, highly permeable APIs displayed a better correlation between predicted and observed AUC compared with low permeable compounds (R: 0.199 and -0.0389 and CCC: 0.195 and -0.0110; Figure 9C).

Predictions of $\mathrm{F}_{\text {oral }}$ in relation to estimated $\mathrm{f}_{\mathrm{a}}$ gave comparable percent within two and threefold whereas APIs with higher estimated $f_{a} \geq 0.9$ displayed a larger percentage within tenfold as compared to the $f_{a}<0.9$ group $\left(100 \%\right.$ vs. $83.3 \%$; Figure 9D). The $f_{a} \geq 0.9$ group displayed a lower bias and higher precision as compared to the $f_{a}<0.9$ group, with AFE of 1.47 and 0.499 , respectively and AAFE of 1.83 and 2.53 (Figure 9E). Correlation coefficients $\mathrm{R}$ and CCC suggested similar correlations between predicted and observed $\mathrm{F}_{\text {oral }}$ for the two groups with a slight favour towards $f_{a} \geq 0.9(\mathrm{R}: 0.517, \mathrm{CCC}: 0.439)$ as compared to $\mathrm{f}_{\mathrm{a}}<0.9$ (R: 0.451, CCC: 0.373; Figure 9F). 

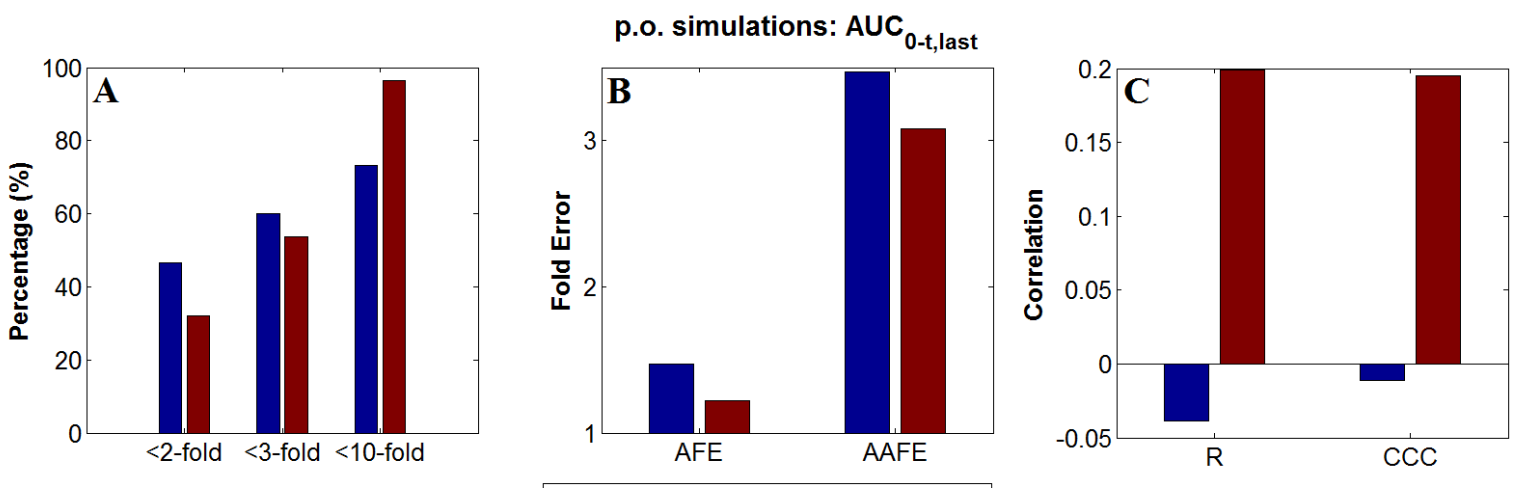

fa $<0.9(n=15) \square$ fa $\geq 0.9(n=28)$
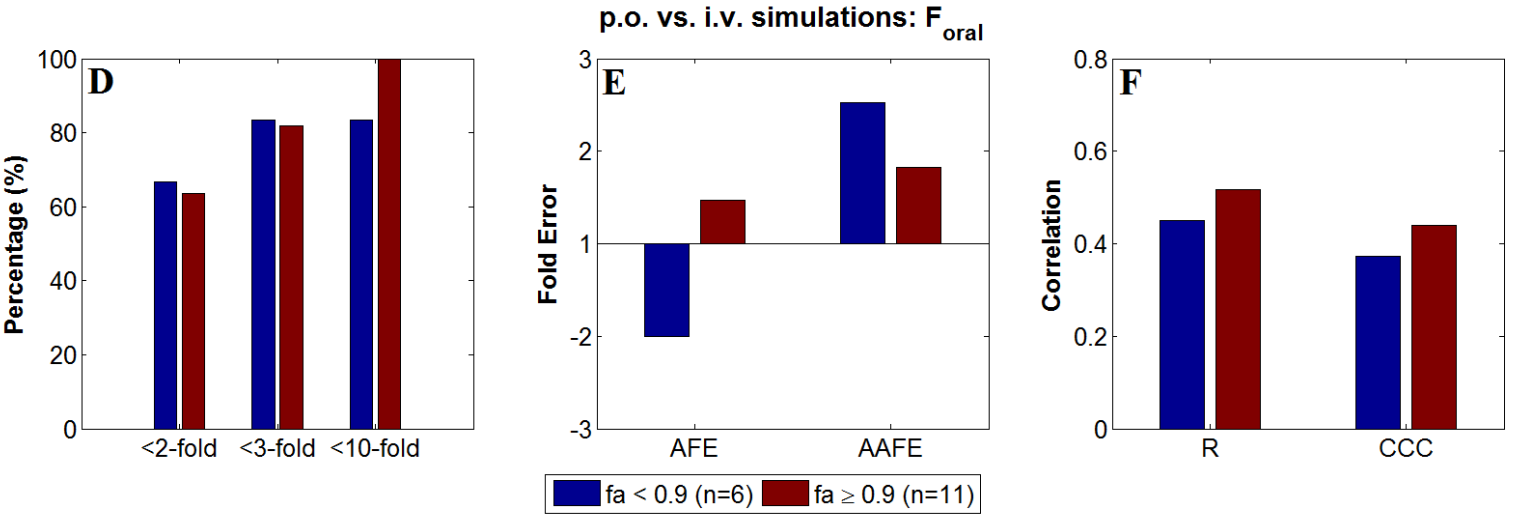

Figure 9: Statistical metrics of prediction success of oral $\mathrm{AUC}_{0-\mathrm{t}, \text { last }}(\mathrm{A}-\mathrm{C})$ and $\mathrm{F}_{\text {oral }}(\mathrm{D}-\mathrm{F})$ as compared to the biopharmaceutics classification system (BCS) cut-off point for permeability $\left(f_{a}=0.9\right)$ divided into permeability-limited $\left(f_{a}<0.9\right)$ and highly permeable $\left(f_{a} \geq 0.9\right)$ active pharmaceutical ingredients (APIs).

\subsubsection{Dose number $\left(D_{0}\right)$}

Examining the predictive success of oral $\mathrm{AUC}_{0-\mathrm{t}, \text { last }}$ in relation to dose number grouping revealed a comparable percentage within two, three and ten-fold. Freely soluble APIs displayed 37.5, 62.5 and $87.5 \%$ within two, three and ten-fold and solubility-limited compounds displayed 37.1, 54.3 and $88.6 \%$ within two, three and ten-fold, respectively. Freely soluble drugs displayed improved AFE and AAFE as compared to solubility-limited compounds, with an AFE of 0.796 (or 1.26-fold underprediction) compared to 1.46 for $\mathrm{D}_{\mathrm{o}} \leq 1$ 
and $\mathrm{D}_{\mathrm{o}}>1$ and AAFE of 2.81 and 3.31. There was an apparent difference in R and CCC for predicted vs. observed oral data for APIs divided based on the $\mathrm{D}_{\mathrm{o}}$ cut-off point, with calculated R coefficients of 0.850 and 0.0684 for $\mathrm{D}_{\mathrm{o}} \leq 1$ and $\mathrm{D}_{\mathrm{o}}>1$, , and CCC of 0.837 and 0.0640 (Figure 10).

There were only 86 simulations and 3 APIs in the $D_{0} \leq 1$ group for which $F_{\text {rel }}$ was obtainable, whereas there were 594 simulations and 21 APIs in the $D_{0}>1$ enabling calculation of $F_{\text {rel }}$. Thus, there were a very limited number of comparators in the $\mathrm{D}_{\mathrm{o}} \leq 1$ group. However, the two groups displayed comparable percent within two, three, and ten-fold $(66.7 \%, 66.7 \%$ and $100 \%$, respectively for $\mathrm{D}_{\mathrm{o}} \leq 1$ and $76.2 \%, 81 \%$ and $100 \%$ for $\mathrm{D}_{\mathrm{o}}>1$ ), and comparable precision with AAFE of 1.66 and 1.67 for $\mathrm{D}_{\mathrm{o}} \leq 1$ and $\mathrm{D}_{\mathrm{o}}>1$. One area of noticeable difference was in the overall bias of the $F_{\text {rel }}$ predictions, for which the $D_{0}>1$ group displayed an overall negative bias with AFE of 0.681 (a 1.47-fold underprediction) and the $\mathrm{D}_{\mathrm{o}} \leq 1$ group displayed a positive bias with an AFE of 1.38 (Figure 10).

Freely soluble APIs (compounds with $\mathrm{D}_{\mathrm{o}} \leq 1$ ) displayed slightly poorer performance in $\mathrm{C}_{\max }$ prediction with respect to percent within $\mathrm{N}$-fold, AFE and AAFE, while displaying a minor improvement in correlation between predicted and observed $\mathrm{C}_{\max }$, $(\mathrm{R}$ and $\mathrm{CCC}$ of 0.627 and 0.533, respectively, vs. 0.442 and 0.438 for solubility limited compounds; Table A2). 

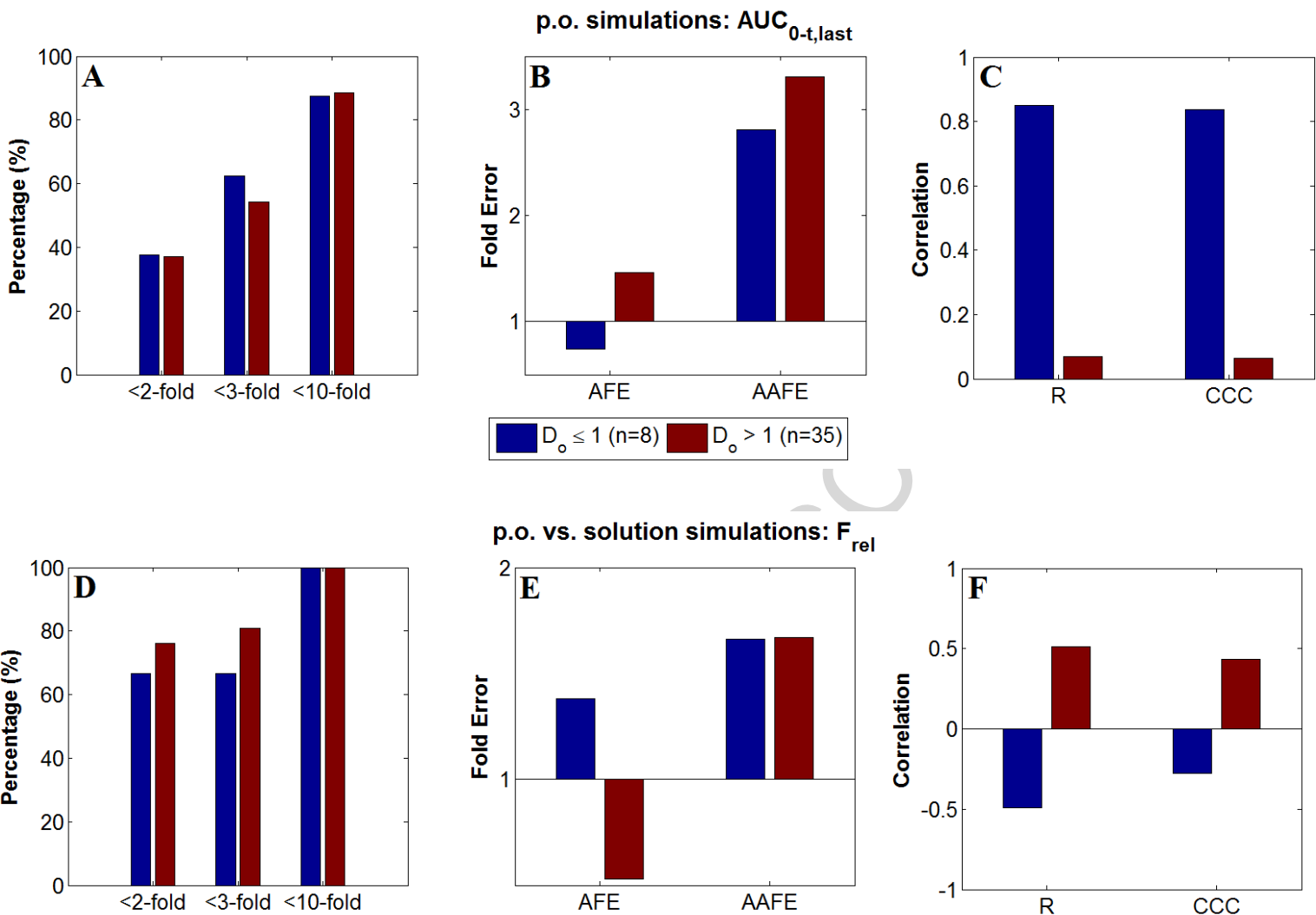

p.o. vs. solution simulations: $F_{\text {rel }}$
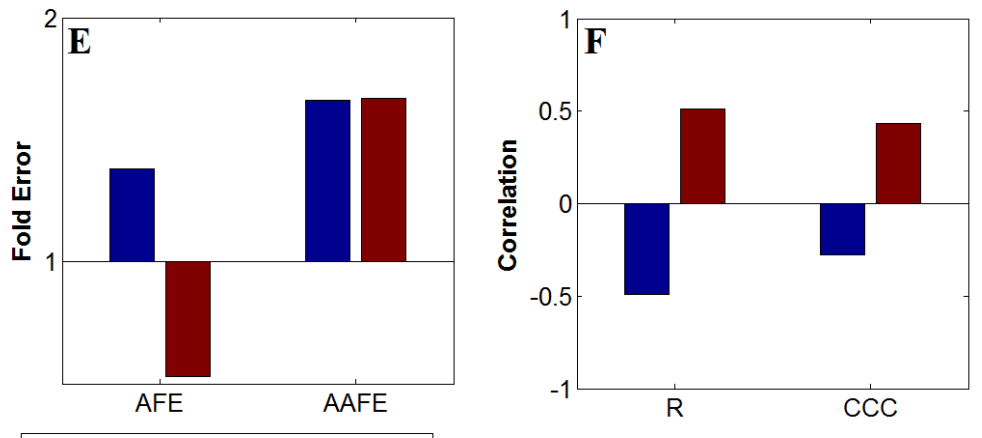

$D_{\circ} \leq 1(n=3) \square D_{\circ}>1(n=21)$

Figure 10: Statistical metrics of prediction success of oral $\mathrm{AUC}_{0-\mathrm{t}, \text { last }}(\mathrm{A}-\mathrm{C})$ and $\mathrm{F}_{\text {rel }}(\mathrm{D}-\mathrm{F})$ as compared to the biopharmaceutics classification system (BCS) dose number $\left(\mathrm{D}_{\mathrm{o}}\right)$ divided into freely soluble $\left(D_{0} \leq 1\right)$ and solubility limited $\left(D_{0}>1\right)$ drug substances.

\subsection{Interpretation}

The purpose of this large-scale simulation exercise was to evaluate and identify areas for improvement in the current PBPK modelling approach to predicting oral exposure, bioavailability and biopharmaceutics effects. The analysis of the simulation exercise managed to highlight both cases where the PBPK absorption modelling approach performed in line with clinical data and cases within the drug-specific parameter space where simulations deviated from the expected. 
There are challenges in interpreting the results of this analysis, as performance is a function of data, model and modeller. Data to inform parameters may be of varied quality and in many cases was lacking, and clinical data may be misrepresentative due to low sample sizes or high variability. Models may fail to appropriately describe gastrointestinal physiology, morphology and the underlying processes governing $\mathrm{F}_{\text {oral }}$. The modellers' interpretation and selection of input parameters can also significantly impact performance.

One should be cautious when interpreting the impact of drug-specific properties on the success of PBPK predictions of oral exposure in the current study, due to the heterogeneity and variable nature of the analysed dataset. There was lack of uniformity in reported API parameter data, with data sources and availability of preclinical and clinical data differing widely between APIs. There was also an intention to examine the impact of user differences on the prediction success, thus modellers were relatively unrestricted in their selections of input data and modelling approaches. Some of these decisions included: Selection of clearance sources for extrapolation, methods for estimating volume of distribution, permeability assays used to inform $\mathrm{P}_{\text {eff }}$, selection of solubility and/or dissolution sources and formulation properties. Further, simulations were carried out only for APIs which fulfilled minimal criteria for available data with a degree of missingness allowed for certain parameters (BP and $\log \mathrm{P})$ which were replaced with estimates.

The high degree of missingness together with a lack of information regarding experimental protocols could be attributed to historical compounds for which key information was not generated, including for example information on the contribution of metabolic pathways, main route of elimination and biorelevant solubility. However, the prevalence of historic 
compounds within the OrBiTo database could not be confirmed due to its blinded nature. Certain elements of missing information may also be due to lack of data or the inability to disclose data to outside parties. Other reasons for missing information may be due to unclear standards for the information required and/or desired for prospective PBPK modelling, e.g. lack of pre-clinical data for a number of APIs. The key missing data which may influence model performance will be addressed throughout the OrBiTo project through EFPIA effort in generating the data and updating their dataset.

Limitations of the simulation exercise put into question whether a true evaluation of PBPK absorption model performance was in fact successful. One can argue that without a full dataset of input parameters to inform the model the boundaries cannot fully be tested. The utilisation of a minimum set of input parameters in most cases will result in an advanced model collapsing down to a simpler one, e.g. a lack of particle size distributional parameters for a given formulation will collapse down to modelling a single uniform particle size (measured or assumed).

However, the broad spectrum analysis of this exercise was able to identify several areas for future model improvement and key inputs needed for building a robust model, which may not have been possible with a smaller scale evaluation of a more data-rich compound set (Table 3). Cautious interpretation of the current findings can be used to inform future directions for improvement of in silico models and available inputs, which should then be evaluated with more targeted test sets. For example, a set of data-rich compounds of high lipophilicity and low aqueous solubility, but relatively high in vivo relative bioavailability could be used to test improvements in in silico biorelevant solubility predictions. A set of data-rich BCS III 
compounds with high solubility and low fraction absorbed could be used to evaluate improvements of intestinal surface area estimates and the contribution of colonic absorption.

Table 3: Areas for Improvement Checklist

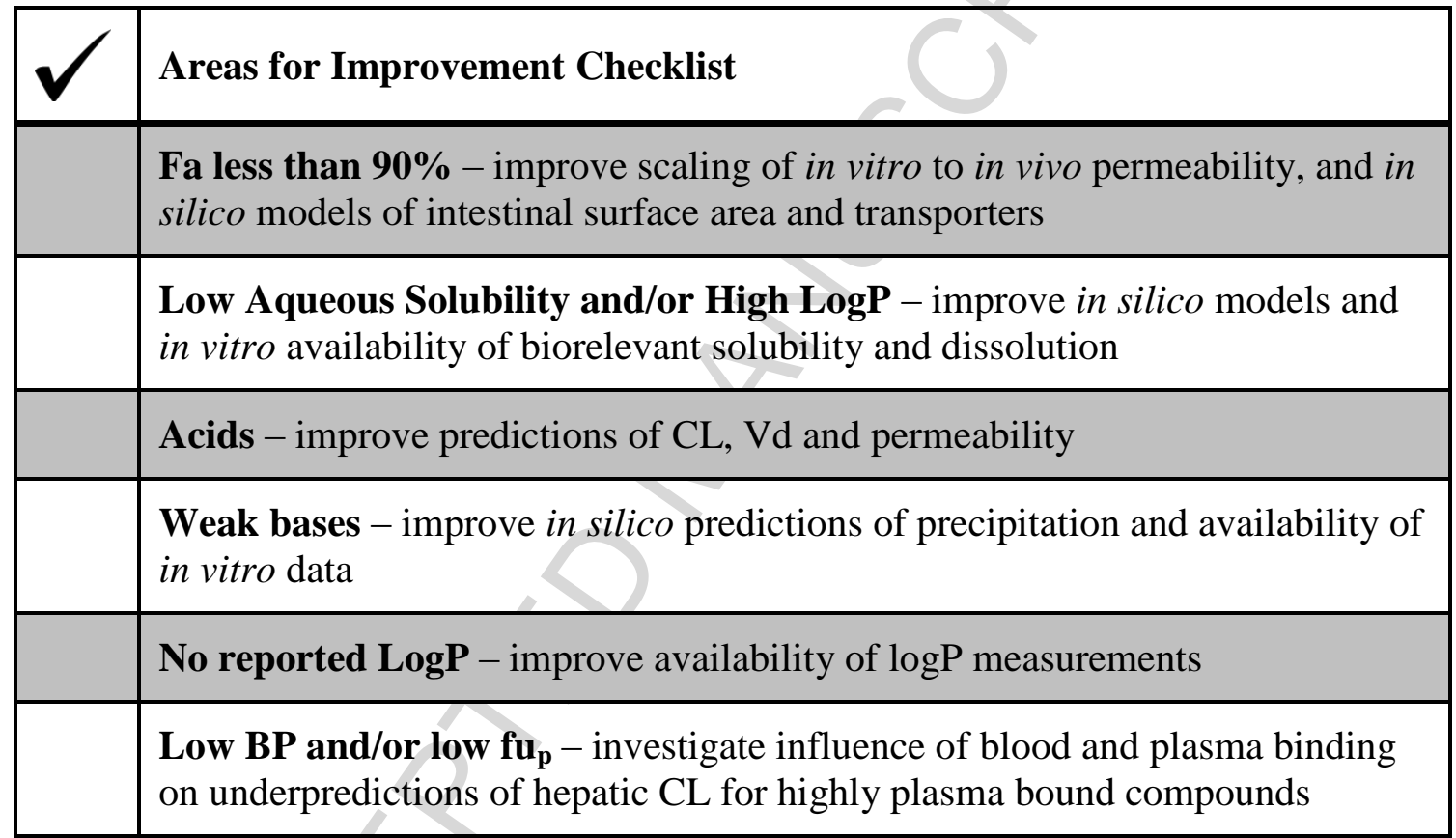

Several tasks are identified in OrBiTo WP4 and across the whole consortium to address the points highlighted in this paper. One task addresses the dynamic calculation of bile salt concentration in the GI tract, while another is making changes to the GI tract physiology, and proposing a more biorelevant model for gastric emptying, lumen and mucosal liquid volumes, together with a gallbladder emptying model. Other projects include proposing new models for supersaturation and precipitation, new algorithms for passive and active permeability and finally a new model for lymphatic absorption.

In parallel to these model improvements, the learning of where models perform well and where they need to improve will also guide the future data collection work or data completion 
work needed from the EFPIA companies. The database will be complemented with missing information on existing drug records such as $\mathrm{rCYP}$ in vitro characterisation of Vmax and $\mathrm{Km}$ of the main enzymes involved in the drug metabolism when pre-systemic extraction is suspected, measurements of $\log \mathrm{P}, \mathrm{pKa}$, aqueous solubility or solubility in biorelevant media. This work also highlights the need for more EFPIA examples of drugs that are relevant for intestinal absorption and oral formulation modelling such as poorly absorbed compounds and weak bases with their precipitation characterisation. All of these examples if they exist could be fed into the OrBiTo database in order to enrich the dataset with more relevant examples.

\section{Conclusion}

The results of this exercise suggest that PBPK modelling of oral bioavailability generally performs well for well-behaved compounds (e.g. neutral or strong base, mid-range logP (2.545 to 3.3), high permeability, high solubility, $\mathrm{BP}>0.64$ and $\left.\mathrm{fu}_{\mathrm{p}}>0.05\right)$. However, as shown in this study, an increasing level of complexity, e.g. solubility and permeability limitations, and increasing complexity of delivery system, were met with decreased prediction performance. In such scenarios, modelling efforts may rely more heavily on quality of input data, model assumptions, and modeller experience. It would therefore be advisable to take into account the increasing degree of uncertainty on prediction success.

For interpreting the results of this study, one must take into perspective the level of availability, detail and quality of data that was used to generate simulations as well as the limitation in contact that could occur between modellers and API owners which would normally occur in the pharmaceutical industry. As such, this approach therefore can be regarded as an opportunistic blinded modelling exercise driven by availability of parameter data. It is the opinion of the authors' that future similar simulation exercises should strive for a more synergistic approach between data gathering and model building in order to ensure the 
exercise to produce relevant results. Further analysis of the simulation output is required to explore the performance of formulation and food effects.

\section{Acknowledgements}

This work was performed under the OrBiTo Project, which has received support from the

Innovative Medicines Joint Undertaking (http://www.imi.europa.eu) under Grant Agreement

No. 115369. The authors would also like to acknowledge the contributions of all participants

in the OrBiTo simulation exercise, especially those who could not be named in the author list.

The extensive list of participants and their affiliations follows below, organised in decreasing order of workload by institution, and then alphabetical order by last name:

\begin{tabular}{|c|c|c|}
\hline Name & Affiliation(s) & Contributions(s) \\
\hline Leon Aarons & University of Manchester & PI for University of Manchester \\
\hline Adam S. Darwich & University of Manchester & $\begin{array}{l}\text { Performed gap analysis on database, } \\
\text { performed simulations, analysed results }\end{array}$ \\
\hline Aleksandra Galetin & University of Manchester & PI for University of Manchester \\
\hline Alison Margolskee & University of Manchester & $\begin{array}{l}\text { Performed gap analysis on database, } \\
\text { performed simulations, analysed results }\end{array}$ \\
\hline Amin Rostami-Hodjegan & $\begin{array}{l}\text { University of } \\
\text { Manchester/SimCYP }\end{array}$ & $\begin{array}{l}\text { Work package co-leader, PI for University } \\
\text { of Manchester, PI for SimCYP }\end{array}$ \\
\hline Sara Carlert & AstraZeneca & Performed simulations, analysed results \\
\hline Maria Hammarberg & AstraZeneca & Performed simulations \\
\hline Constanze Hilgendorf & AstraZeneca & Performed simulations \\
\hline Pernilla Johansson & AstraZeneca & Performed simulations \\
\hline Eva Karlsson & AstraZeneca & Performed simulations \\
\hline Donal Murphy & AstraZeneca & Performed simulations \\
\hline Christer Tannergren & AstraZeneca & Performed simulations, PI for AstraZeneca \\
\hline Helena Thörn & AstraZeneca & Performed simulations \\
\hline Mohammed Yasin & AstraZeneca & Performed simulations \\
\hline Florent Mazuir & Sanofi & Performed simulations \\
\hline Olivier Nicolas & Sanofi & Performed simulations, analysed results \\
\hline Xavier Pepin & Sanofi/AstraZeneca & $\begin{array}{l}\text { Work package co-leader, PI for Sanofi until } \\
\text { March 2015, performed gap analysis on } \\
\text { database, performed simulations, analysed } \\
\text { results }\end{array}$ \\
\hline Sergej Ramusovic & Sanofi & Performed simulations \\
\hline Christine Xu & Sanofi & Performed simulations \\
\hline Shriram Pathak & SimCYP & $\begin{array}{l}\text { Performed gap analysis on database, } \\
\text { performed simulations, analysed results }\end{array}$ \\
\hline
\end{tabular}




\begin{tabular}{|c|c|c|}
\hline Timo Korjamo & Orion Pharma & Performed simulations, analysed results \\
\hline Johanna Laru & Orion Pharma & Performed simulations \\
\hline Jussi Malkki & Orion Pharma & Performed simulations, analysed results \\
\hline Sari Pappinen & Orion Pharma & Analysed results \\
\hline Johanna Tuunainen & Orion Pharma & Analysed results \\
\hline Jennifer Dressman & Goethe University & PI for Goethe University \\
\hline Carmen Gött & Goethe University & Analysed results \\
\hline Simone Hansmann & Goethe University & Performed simulations, analysed results \\
\hline Edmund Kostewicz & Goethe University & PI for Goethe University \\
\hline Handan He & Novartis & Performed simulations, analysed results \\
\hline Tycho Heimbach & Novartis & Performed simulations, analysed results \\
\hline Fan Wu & Novartis & Performed simulations, analysed results \\
\hline Carolin Hoft & AbbVie & Performed simulations \\
\hline Yan Pang & AbbVie & Performed simulations \\
\hline Michael B. Bolger & Simulations Plus & $\begin{array}{l}\text { PI for Simulations Plus, lead for analysis of } \\
\text { impact of solubility and dissolution }\end{array}$ \\
\hline John DiBella & Simulations Plus & $\begin{array}{l}\text { Financial and time accounting for } \\
\text { Simulations Plus }\end{array}$ \\
\hline Eva Huehn & Simulations Plus & $\begin{array}{l}\text { Performed gap analysis on database, } \\
\text { performed simulations }\end{array}$ \\
\hline Viera Lukacova & Simulations Plus & Co-PI for Simulations Plus \\
\hline James M. Mullin & Simulations Plus & $\begin{array}{l}\text { Performed gap analysis on database, } \\
\text { performed simulations }\end{array}$ \\
\hline Ke X. Szeto & Simulations Plus & $\begin{array}{l}\text { Performed gap analysis on database, } \\
\text { performed simulations }\end{array}$ \\
\hline Joanne Bennett & Pfizer & Collation of data for database \\
\hline Chester Costales & Pfizer & Performed simulations \\
\hline Jian Lin & Pfizer & Performed simulations \\
\hline Mark McAllister & Pfizer & Performed simulations \\
\hline Sweta Modi & Pfizer & Performed simulations \\
\hline Charles Rotter & Pfizer & Performed simulations \\
\hline Manthena Varma & Pfizer & Performed simulations \\
\hline Mei Wong & Pfizer & Performed simulations \\
\hline Amitava Mitra & $\begin{array}{l}\text { Merck Sharp \& Dohme } \\
\text { (MSD) }\end{array}$ & Performed simulations, analysed results \\
\hline Jan Bevernage & Janssen & Performed simulations \\
\hline Jeike Biewenga & Janssen & Performed simulations \\
\hline Achiel Van Peer & Janssen & Performed simulations \\
\hline Richard Lloyd & GlaxoSmithKline & Performed simulations, analysed results \\
\hline Carole Shardlow & GlaxoSmithKline & Performed simulations, analysed results \\
\hline Peter Langguth & University of Mainz & PI for University of Mainz \\
\hline Irina Mishenzon & University of Mainz & Performed simulations \\
\hline Mai Anh Nguyen & University of Mainz & Performed simulations \\
\hline Jonathan Brown & Bristol-Myers Squibb & Performed simulations \\
\hline
\end{tabular}




\section{References}

Berezhkovskiy LM (2004) Volume of distribution at steady state for a linear pharmacokinetic system with peripheral elimination. J Pharm Sci 93:1628-1640.

Hallifax D and Houston JB (2006) Binding of drugs to hepatic microsomes: comment and assessment of current prediction methodology with recommendation for improvement. Drug Metab Dispos 34:724-726; author reply 727.

Hallifax D, Turlizzi E, Zanelli U, and Houston JB (2012) Clearance-dependent underprediction of in vivo intrinsic clearance from human hepatocytes: comparison with permeabilities from artificial membrane (PAMPA) assay, in silico and caco-2 assay, for 65 drugs. Eur J Pharm Sci 45:570-574.

Lennernas H, Aarons L, Augustijns P, Beato S, Bolger M, Box K, Brewster M, Butler J, Dressman J, Holm R, Julia Frank K, Kendall R, Langguth P, Sydor J, Lindahl A, McAllister M, Muenster U, Mullertz A, Ojala K, Pepin X, Reppas C, RostamiHodjegan A, Verwei M, Weitschies W, Wilson C, Karlsson C, and Abrahamsson B (2014) Oral biopharmaceutics tools - Time for a new initiative - An introduction to the IMI project OrBiTo. Eur J Pharm Sci. 57:292-299.

Lin L (1989) A Concordance Correlation Coefficient to Evaluate Reproducibility. Biometrics 45:255-268.

Margolskee A, Darwich AS, Pepin X, Pathak SM, Bolger MB, Aarons L, Rostami-Hodjegan A, Angstenberger J, Graf F, Laplanche L, Müller T, Carlert S, Daga P, Murphy D, Tannergren C, Yasin M, Greschat-Schade S, Mück W, Muenster U, van der Mey D, Frank KJ, Lloyd R, Adriaenssen L, Bevernage J, De Zwart L, Swerts D, Tistaert C, Van Den Bergh A, Van Peer A, Beato S, Nguyen-Trung AT, Bennett J, McAllister M, Wong M, Zane P, Ollier C, Vicat P, Kolhmann M, Marker A, Brun P, Mazuir F, Beilles S, Venczel M, Boulenc X, Loos P, Lennernäs H, Abrahamsson B (Submitted) IMI - Oral Biopharmaceutics Tools project - Evaluation of Bottom-up PBPK Prediction Success Part 1: Characterisation of the OrBiTo Database of Compounds. Eur J Pharm Sci.

Margolskee A, Darwich A, Pepin X, Aarons L, Galetin A, Rostami-Hodjegan A, Carlert S, Hammarberg M, Hilgendorf C, Johansson P, Karlsson E, Murphy D, Tannergren C, Thorn H, Yasin M, Mazuir F, Nicolas O, Ramusovic S, Xu C, Pathak SM, Korjamo T, Laur J, Malkki J, Pappinen S, Tuunainen J, Dressman J, Hansmann S, Kostewicz E, He H, Heimbach T, Wu F, Hoft C, Laplanche L, Pang Y, Bolger MB, Huehn E, Lukacova V, Mullin JM, Szeto KX, Costales C, Lin J, McAllister M, Modi S, Rotter C, Varma M, Wong M, Mitra A, Bevernage J, Biewenga J, Van Peer A, Lloyd R, Shardlow C, Langguth P, Mishenzon I, Nguyen MA, Brown J, Lennernas H, and Abrahamsson B (Submitted) IMI - Oral Biopharmaceutics Tools project - Evaluation of Bottom-up PBPK Prediction Success Part 2: An Introduction to the Simulation Exercise and Overview of Results. Eur J Pharm Sci.

Miller JM, Beig A, Krieg BJ, Carr RA, Borchardt TB, Amidon GE, Amidon GL, and Dahan A (2011) The Solubility-Permeability Interplay: Mechanistic Modeling and 
Predictive Application of the Impact of Micellar Solubilization on Intestinal Permeation. Molecular Pharmaceutics 8(5): 1848-1856

Mithani SD, Bakatselou V, TenHoor CN, and Dressman JB (1996) Estimation of the increase in solubility of drugs as a function of bile salt concentration. Pharm Res 13:163-167.

Poulin P and Haddad S (2012) Advancing prediction of tissue distribution and volume of distribution of highly lipophilic compounds from a simplified tissue-compositionbased model as a mechanistic animal alternative method. J Pharm Sci 101:2250-2261.

Poulin P, Jones HM, Jones RD, Yates JW, Gibson CR, Chien JY, Ring BJ, Adkison KK, He H, Vuppugalla R, Marathe P, Fischer V, Dutta S, Sinha VK, Bjornsson T, Lave T, and Ku MS (2011) PhRMA CPCDC initiative on predictive models of human pharmacokinetics, part 1: Goals, properties of the PhRMA dataset, and comparison with literature datasets. J Pharm Sci. 100(10):4050-4073.

Poulin P and Theil FP (2000) A priori prediction of tissue:plasma partition coefficients of drugs to facilitate the use of physiologically-based pharmacokinetic models in drug discovery. J Pharm Sci 89:16-35.

Rodgers T, Leahy D, and Rowland M (2005) Physiologically based pharmacokinetic modeling 1: predicting the tissue distribution of moderate-to-strong bases. J Pharm Sci 94:1259-1276.

Rodgers T and Rowland M (2006) Physiologically based pharmacokinetic modelling 2: predicting the tissue distribution of acids, very weak bases, neutrals and zwitterions. $J$ Pharm Sci 95:1238-1257.

Yamazaki K and Kanaoka M (2004) Computational prediction of the plasma protein-binding percent of diverse pharmaceutical compounds. J Pharm Sci 93:1480-1494. 


\section{Appendix}

Table A1: Summary statistics for $\mathrm{AUC}_{0-\mathrm{t}, \mathrm{last}}$ predictions for p.o. simulations, grouped by different compound specific properties.

\begin{tabular}{|c|c|c|c|c|c|c|c|c|c|c|}
\hline & $\begin{array}{l}\text { no. } \\
\text { APIs }\end{array}$ & $\begin{array}{l}\% \\
\text { within } \\
2 \text { fold }\end{array}$ & $\begin{array}{l}\% \\
\text { within } \\
3 \text { fold }\end{array}$ & $\begin{array}{l}\% \\
\text { within } \\
10 \text { fold }\end{array}$ & AFE & AAFE & $\mathbf{R}$ & $\mathrm{CCC}$ & $\begin{array}{l}\text { R } \\
\text { (of log } \\
\text { data) }\end{array}$ & $\begin{array}{l}\text { CCC } \\
\text { (of log } \\
\text { data) }\end{array}$ \\
\hline \multicolumn{11}{|l|}{ Molecular Weight } \\
\hline Q1: $(150,365 \mathrm{~g} / \mathrm{mol}]$ & 11 & 27.3 & 54.5 & 81.8 & 1.25 & 3.91 & -0.129 & -0.0427 & 0.486 & 0.453 \\
\hline Q2: $(365,440 \mathrm{~g} / \mathrm{mol}]$ & 10 & 40.0 & 50.0 & 80.0 & 0.604 & 3.36 & 0.0851 & 0.0784 & 0.734 & 0.712 \\
\hline Q3: $(440,505 \mathrm{~g} / \mathrm{mol}]$ & 11 & 36.4 & 54.5 & 100 & 2.32 & 2.75 & 0.557 & 0.439 & 0.952 & 0.884 \\
\hline Q4: $(505,870 \mathrm{~g} / \mathrm{mol}]$ & 11 & 45.5 & 63.6 & 90.9 & 1.53 & 2.94 & 0.372 & 0.186 & 0.744 & 0.728 \\
\hline \multicolumn{11}{|l|}{ Acid/Base Nature } \\
\hline Acid & 10 & 10.0 & 20.0 & 70.0 & 1.16 & 6.33 & -0.0921 & -0.0480 & 0.713 & 0.700 \\
\hline Ampholyte & 4 & 0.00 & 25.0 & 50.0 & 1.81 & 9.54 & -0.284 & -0.0559 & 0.723 & 0.516 \\
\hline Neutral & 5 & 40.0 & 80.0 & 100 & 1.92 & 1.92 & 0.891 & 0.340 & 0.836 & 0.541 \\
\hline Weak Base & 11 & 36.4 & 45.5 & 100 & 1.30 & 3.26 & 0.641 & 0.380 & 0.736 & 0.679 \\
\hline Strong Base & 13 & 69.2 & 92.3 & 100 & 1.11 & 1.63 & 0.929 & 0.928 & 0.949 & 0.947 \\
\hline \multicolumn{11}{|l|}{$\log P$} \\
\hline Q1: $(-0.72,2.545]$ & 9 & 44.4 & 66.7 & 88.9 & 1.83 & 3.34 & 0.0411 & 0.0183 & 0.495 & 0.444 \\
\hline Q2: $(2.545,3.3]$ & 9 & 55.6 & 66.7 & 100 & 1.14 & 2.17 & 0.862 & 0.836 & 0.803 & 0.784 \\
\hline Q3: $(3.3,4.49]$ & 8 & 37.5 & 62.5 & 87.5 & 1.86 & 3.32 & 0.465 & 0.183 & 0.461 & 0.423 \\
\hline Q4: (4.49, 7.75] & 9 & 33.3 & 55.6 & 77.8 & 0.899 & 3.03 & 0.0489 & 0.0481 & 0.878 & 0.877 \\
\hline Not Given & 8 & 12.5 & 25.0 & 87.5 & 1.11 & 4.91 & -0.0936 & -0.0913 & 0.483 & 0.483 \\
\hline $\operatorname{LogD}$ & 4 & 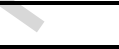 & & & & & & & & \\
\hline Q1: (-1.45,1.29] & 7 & 14.3 & 28.6 & 57.1 & 2.19 & 7.59 & -0.239 & -0.083 & 0.457 & 0.425 \\
\hline Q2: $(1.29,2.55]$ & 7 & 42.9 & 42.9 & 100 & 1.54 & 3.01 & 0.885 & 0.241 & 0.712 & 0.600 \\
\hline Q3: $(2.55,3.17]$ & 7 & 42.9 & 57.1 & 85.7 & 0.648 & 3.86 & 0.0692 & 0.016 & 0.541 & 0.515 \\
\hline Q4: $(3.17,5.8]$ & 7 & 14.3 & 57.1 & 85.7 & 1.53 & 3.04 & 0.887 & 0.432 & 0.717 & 0.695 \\
\hline Not Given & 15 & 53.3 & 73.3 & 100 & 1.22 & 2.08 & 0.846 & 0.834 & 0.944 & 0.937 \\
\hline \multicolumn{11}{|l|}{ BCS Classification } \\
\hline BCS class I & 8 & 37.5 & 62.5 & 87.5 & 0.796 & 2.81 & 0.850 & 0.837 & 0.765 & 0.740 \\
\hline BCS class II & 24 & 33.3 & 54.2 & 91.7 & 1.55 & 3.30 & 0.0327 & 0.0304 & 0.780 & 0.759 \\
\hline BCS class III & 2 & 100 & 100 & 100 & 0.694 & 1.44 & 1.00 & 0.0923 & 1.00 & 0.132 \\
\hline BCS class IV & 9 & 33.3 & 44.4 & 77.8 & 1.47 & 4.00 & 0.103 & 0.0995 & 0.751 & 0.727 \\
\hline \multicolumn{11}{|l|}{ Dose number } \\
\hline $\mathrm{D}_{0} \leq 1$ & 8 & 37.5 & 62.5 & 87.5 & 0.796 & 2.81 & 0.85 & 0.837 & 0.765 & 0.74 \\
\hline $\mathrm{D}_{0}>1$ & 35 & 37.1 & 54.3 & 88.6 & 1.46 & 3.31 & 0.0684 & 0.064 & 0.77 & 0.759 \\
\hline \multicolumn{11}{|l|}{ Estimated fa } \\
\hline $\mathbf{f}_{\mathrm{a}}<0.9$ & 15 & 46.7 & 60 & 73.3 & 1.47 & 3.47 & -0.0389 & -0.0110 & 0.776 & 0.768 \\
\hline$f_{a} \geq 0.9$ & 28 & 32.1 & 53.6 & 96.4 & 1.22 & 3.08 & 0.199 & 0.195 & 0.728 & 0.72 \\
\hline \multicolumn{11}{|l|}{$\mathbf{B P}$} \\
\hline Q1: $(0.517,0.595]$ & 11 & 0.00 & 27.3 & 72.7 & 0.951 & 5.91 & 0.0147 & 0.0136 & 0.702 & 0.701 \\
\hline Q2: $(0.595,0.640]$ & 9 & 33.3 & 44.4 & 77.8 & 2.13 & 4.46 & -0.112 & -0.101 & 0.787 & 0.761 \\
\hline Q3: $(0.640,0.925]$ & 12 & 50.0 & 66.7 & 100 & 1.57 & 2.12 & 0.825 & 0.727 & 0.831 & 0.786 \\
\hline Q4: $(0.925,3.300]$ & 11 & 63.6 & 81.8 & 100 & 0.98 & 2.09 & 0.921 & 0.908 & 0.807 & 0.802 \\
\hline \multicolumn{11}{|l|}{$\mathbf{f u}_{\mathrm{p}}$} \\
\hline Q1: $(0.0002,0.0125]$ & 11 & 27.3 & 45.5 & 72.7 & 1.41 & 4.54 & -0.0658 & -0.0614 & 0.811 & 0.804 \\
\hline Q2: $(0.0125,0.05]$ & 10 & 40.0 & 60.0 & 90.0 & 1.04 & 2.84 & 0.00985 & 0.00851 & 0.587 & 0.577 \\
\hline
\end{tabular}


Table A2: Summary statistics for $\mathrm{C}_{\max }$ predictions for p.o. simulations, grouped by different compound specific properties.

\begin{tabular}{|c|c|c|c|c|c|c|c|c|c|c|}
\hline & $\begin{array}{l}\text { no. } \\
\text { APIs }\end{array}$ & $\begin{array}{l}\% \\
\text { within } \\
2 \text { fold }\end{array}$ & $\begin{array}{l}\% \\
\text { within } \\
3 \text { fold }\end{array}$ & $\begin{array}{l}\% \\
\text { within } \\
10 \text { fold }\end{array}$ & AFE & AAFE & $\mathbf{R}$ & $\mathrm{CCC}$ & $\begin{array}{l}R \\
\text { (of log } \\
\text { data) }\end{array}$ & $\begin{array}{l}\text { CCC } \\
\text { (of log } \\
\text { data) }\end{array}$ \\
\hline \multicolumn{11}{|l|}{ Molecular Weight } \\
\hline Q1: $(150,365 \mathrm{~g} / \mathrm{mol}]$ & 11 & 27.3 & 45.5 & 81.8 & 0.612 & 4.07 & 0.178 & 0.176 & 0.596 & 0.558 \\
\hline Q2: $(365,440 \mathrm{~g} / \mathrm{mol}]$ & 10 & 50.0 & 60.0 & 80.0 & 0.416 & 3.20 & 0.478 & 0.388 & 0.761 & 0.692 \\
\hline Q3: (440,505 g/mol] & 11 & 54.5 & 81.8 & 90.9 & 0.819 & 2.36 & 0.969 & 0.631 & 0.952 & 0.867 \\
\hline Q4: $(505,870 \mathrm{~g} / \mathrm{mol}]$ & 11 & 27.3 & 63.6 & 90.9 & 0.667 & 3.38 & 0.651 & 0.632 & 0.716 & 0.696 \\
\hline \multicolumn{11}{|l|}{ Acid/Base Nature } \\
\hline Acid & 10 & 10.0 & 30.0 & 60.0 & 0.329 & 7.22 & 0.146 & 0.144 & 0.800 & 0.677 \\
\hline Ampholyte & 4 & 25.0 & 25.0 & 75.0 & 2.00 & 4.21 & 0.668 & 0.228 & 0.932 & 0.706 \\
\hline Neutral & 5 & 60.0 & 100 & 100 & 0.668 & 1.73 & 0.922 & 0.749 & 0.816 & 0.744 \\
\hline Weak Base & 11 & 45.5 & 72.7 & 90.9 & 0.806 & 2.76 & 0.783 & 0.644 & 0.741 & 0.725 \\
\hline Strong Base & 13 & 53.8 & 76.9 & 100 & 0.536 & 2.24 & 0.457 & 0.362 & 0.886 & 0.830 \\
\hline \multicolumn{11}{|l|}{ LogP } \\
\hline Q1: $(-0.72,2.545]$ & 9 & 11.1 & 66.7 & 100 & 0.923 & 2.88 & 0.730 & 0.516 & 0.787 & 0.725 \\
\hline Q2: $(2.545,3.3]$ & 9 & 44.4 & 66.7 & 88.9 & 0.679 & 2.66 & 0.318 & 0.274 & 0.615 & 0.575 \\
\hline Q3: $(3.3,4.49]$ & 8 & 75.0 & 75.0 & 75.0 & 0.925 & 2.72 & 0.610 & 0.530 & 0.105 & 0.105 \\
\hline Q4: $(4.49,7.75]$ & 9 & 33.3 & 55.6 & 66.7 & 0.234 & 5.36 & 0.294 & 0.032 & 0.798 & 0.694 \\
\hline Not $G$ & 8 & 37.5 & $\overline{50.0}$ & 100 & 0.694 & 2.88 & 0.258 & 0.255 & 0.743 & 0.722 \\
\hline $\log D$ & $\bar{z}$ & +2 & & & & & & & & \\
\hline Q1: (-1.4 & 7 & 14.3 & 42.9 & 71.4 & 1.12 & 4.73 & -0.0136 & -0.0131 & 0.632 & 0.61 \\
\hline Q2: (1.2 & 7 & 42.9 & 85.7 & 100 & 0.903 & 2.16 & 0.962 & 0.557 & 0.865 & 0.805 \\
\hline Q3: $(2.55,3.17]$ & 7 & 14.3 & 28.6 & 85.7 & 0.512 & 4.38 & 0.668 & 0.309 & 0.558 & 0.518 \\
\hline Q4: $(3.17,5.8]$ & 7 & 71.4 & 85.7 & 85.7 & 0.645 & 2.48 & 0.778 & 0.751 & 0.683 & 0.665 \\
\hline Not Given & 15 & 46.7 & 66.7 & 86.7 & 0.416 & 3.09 & 0.686 & 0.64 & 0.903 & 0.819 \\
\hline \multicolumn{11}{|l|}{ BCS Classification } \\
\hline BCS class I & 8 & 37.5 & 62.5 & 75.0 & 0.605 & 4.01 & 0.627 & 0.533 & 0.597 & 0.529 \\
\hline BCS class II & 24 & 45.8 & 66.7 & 91.7 & 0.759 & 2.66 & 0.443 & 0.443 & 0.857 & 0.832 \\
\hline BCS class III & 2 & 0.00 & 50.0 & 100 & 0.222 & 4.51 & 1.00 & 0.00868 & 1.00 & 0.0278 \\
\hline BCS class IV & 9 & 33.3 & 55.6 & 77.8 & 0.45 & 3.9 & 0.44 & 0.0493 & 0.708 & 0.646 \\
\hline \multicolumn{11}{|l|}{ Dose number } \\
\hline$D_{0} \leq 1$ & 8 & 37.5 & 62.5 & 75 & 0.605 & 4.01 & 0.627 & 0.533 & 0.597 & 0.529 \\
\hline$D_{0}>1$ & 35 & 40 & 62.9 & 88.6 & 0.619 & 3.03 & 0.442 & 0.438 & 0.818 & 0.791 \\
\hline \multicolumn{11}{|l|}{ Estimated fa } \\
\hline $\mathrm{f}_{\mathrm{a}}<0.9$ & 15 & 20 & 46.7 & 73.3 & 0.337 & 5.05 & 0.0876 & 0.0781 & 0.759 & 0.688 \\
\hline$f_{a} \geq 0.9$ & 28 & 50 & 71.4 & 92.9 & 0.851 & 2.5 & 0.512 & 0.51 & 0.805 & 0.792 \\
\hline \multicolumn{11}{|l|}{$\mathbf{B P}$} \\
\hline Q1: $(0.517,0.595]$ & 11 & 27.3 & 45.5 & 45.5 & 0.247 & 7.36 & 0.242 & 0.224 & 0.698 & 0.604 \\
\hline Q2: $(0.595,0.640]$ & 9 & 44.4 & 66.7 & 100 & 0.889 & 2.58 & 0.425 & 0.421 & 0.946 & 0.927 \\
\hline Q3: $(0.640,0.925]$ & 12 & 50.0 & 75.0 & 100 & 0.903 & 2.01 & 0.678 & 0.340 & 0.821 & 0.812 \\
\hline Q4: (0.925,3.300] & 11 & 36.4 & 63.6 & 100 & 0.75 & 2.73 & 0.760 & 0.636 & 0.746 & 0.722 \\
\hline \multicolumn{11}{|l|}{$f u_{p}$} \\
\hline Q1: (0.0002,0.0125] & 11 & 36.4 & 54.5 & 81.8 & 0.413 & 3.99 & 0.458 & 0.436 & 0.883 & 0.819 \\
\hline Q2: $(0.0125,0.05]$ & 10 & 60.0 & 80.0 & 80.0 & 0.661 & 2.88 & 0.315 & 0.311 & 0.629 & 0.610 \\
\hline
\end{tabular}




\begin{tabular}{r|r|r|r|r|r|}
11 & 45.5 & 63.6 & 100 & 0.839 & \\
11 & 18.2 & 54.5 & 81.8 & 0.633 &
\end{tabular}

\begin{tabular}{l|l|l}
2.40 & & -13 \\
3.73 & &
\end{tabular}

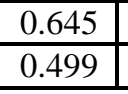

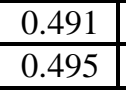

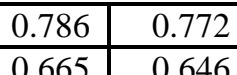

Table A3: Summary statistics for $\mathrm{F}_{\text {oral }}$ predictions between p.o. and i.v. simulations, grouped

by different compound specific properties.

\begin{tabular}{|c|c|c|c|c|c|c|c|c|c|c|}
\hline & $\begin{array}{l}\text { no. } \\
\text { APIs }\end{array}$ & $\begin{array}{l}\% \\
\text { within } \\
2 \text { fold }\end{array}$ & $\begin{array}{l}\% \\
\text { within } \\
3 \text { fold }\end{array}$ & $\begin{array}{l}\% \\
\text { within } \\
10 \text { fold }\end{array}$ & AFE & AAFE & $\mathbf{R}$ & $\mathrm{CCC}$ & $\begin{array}{l}\text { R } \\
\text { (of log } \\
\text { data) }\end{array}$ & $\begin{array}{l}\text { CCC } \\
\text { (of log } \\
\text { data) }\end{array}$ \\
\hline \multicolumn{11}{|l|}{ Molecular Weight } \\
\hline Q1: $(150,365 \mathrm{~g} / \mathrm{mol}]$ & 5 & 100 & 100 & 100 & 1.08 & 1.29 & 0.215 & 0.198 & 0.123 & 0.111 \\
\hline Q2: $(365,440 \mathrm{~g} / \mathrm{mol}]$ & 4 & $\overline{50.0}$ & $\overline{50.0}$ & 75.0 & 0.701 & 3.93 & -0.243 & -0.226 & -0.150 & -0.144 \\
\hline Q3: $(440,505 \mathrm{~g} / \mathrm{mol}]$ & 4 & 75.0 & 100 & 100 & 1.25 & 1.58 & -0.325 & -0.119 & -0.314 & 0.0894 \\
\hline Q4: $(505,870 \mathrm{~g} / \mathrm{mol}]$ & 4 & 25.0 & 75.0 & 100 & 1.05 & 2.47 & -0.156 & -0.127 & 0.222 & 0.221 \\
\hline \multicolumn{11}{|l|}{ Acid/Base Nature } \\
\hline Acid & 5 & 80.0 & 80.0 & 80.0 & 0.581 & 2.40 & -0.574 & -0.478 & -0.512 & -0.189 \\
\hline Ampholyte & 0 & & 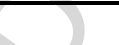 & & & & & & & \\
\hline Neutral & 0 & 7 & $\bar{y}$ & & & & & & & \\
\hline Weak Base & 4 & 25.0 & 75.0 & 100 & 1.48 & 2.46 & -0.557 & -0.296 & -0.485 & -0.363 \\
\hline Strong Base & 8 & 75.0 & 87.5 & 100 & 1.16 & 1.69 & 0.794 & 0.767 & 0.839 & 0.815 \\
\hline $\log P$ & & 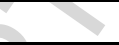 & & & & & & & & \\
\hline Q1: $(-0.72,2.545]$ & 6 & 66.7 & 100 & 100 & 0.819 & 1.61 & 0.671 & 0.607 & 0.729 & 0.548 \\
\hline Q2: $(2.545,3.3]$ & 1 & 100 & 100 & 100 & 0.92 & 1.09 & & & & \\
\hline Q3: $(3.3,4.49]$ & 4 & 50.0 & 50.0 & 100 & 2.21 & 2.29 & 0.464 & 0.170 & 0.554 & 0.125 \\
\hline Q4: $(4.49,7.75]$ & 4 & 75.0 & $\overline{75.0}$ & 75.0 & 0.477 & 3.32 & 0.588 & 0.412 & 0.257 & 0.223 \\
\hline Not Given & 2 & 50.0 & 100 & 100 & 1.76 & 1.76 & -1.00 & -0.236 & -1.00 & -0.231 \\
\hline \multicolumn{11}{|l|}{$\log D$} \\
\hline Q1: $(-1.45,1.29]$ & 3 & 66.7 & 66.7 & 66.7 & 0.418 & 4.17 & -0.855 & -0.706 & -0.823 & -0.283 \\
\hline Q2: $(1.29,2.55]$ & 4 & 25.0 & 100 & 100 & 0.797 & 1.96 & 0.540 & 0.515 & 0.530 & 0.422 \\
\hline Q3: $(2.55,3.17]$ & 1 & 100 & 100 & 100 & 1.59 & 1.59 & & & & \\
\hline Q4: $(3.17,5.8]$ & 4 & 75.0 & 75.0 & 100 & 1.49 & 1.85 & 0.755 & 0.297 & 0.907 & 0.245 \\
\hline Not Given & 5 & 80.0 & 80.0 & 100 & 1.36 & 1.58 & 0.61 & 0.584 & 0.803 & 0.75 \\
\hline \multicolumn{11}{|l|}{ BCS Classification } \\
\hline BCS class I & 3 & 100 & 100 & 100 & 0.94 & 1.06 & 0.928 & 0.653 & 0.928 & 0.66 \\
\hline BCS class II & 9 & 66.7 & 77.8 & 100 & 1.82 & 1.94 & 0.478 & 0.3 & 0.768 & 0.591 \\
\hline BCS class III & 1 & 0.00 & 100 & 100 & 0.497 & 2.01 & & & & \\
\hline BCS class IV & 4 & 50.0 & 75.0 & $\overline{75.0}$ & 0.329 & 3.81 & 0.55 & 0.34 & 0.209 & 0.155 \\
\hline \multicolumn{11}{|l|}{ Dose number } \\
\hline$D_{0} \leq 1$ & 3 & 100 & 100 & 100 & 0.94 & 1.06 & 0.928 & 0.653 & 0.928 & 0.66 \\
\hline$D_{0}>1$ & 14 & 57.1 & 78.6 & 92.9 & 1.02 & 2.36 & 0.18 & 0.179 & 0.286 & 0.283 \\
\hline \multicolumn{11}{|l|}{ Estimated fa } \\
\hline $\mathrm{f}_{\mathrm{a}}<0.9$ & 6 & 66.7 & 83.3 & 83.3 & 0.499 & 2.53 & 0.451 & 0.373 & 0.326 & 0.276 \\
\hline$f_{a} \geq 0.9$ & 11 & 63.6 & 81.8 & 100 & 1.47 & 1.83 & 0.517 & 0.439 & 0.643 & 0.575 \\
\hline \multicolumn{11}{|l|}{ BP } \\
\hline Q1: $(0.517,0.595]$ & 3 & 66.7 & 66.7 & 66.7 & 0.377 & 3.94 & -0.728 & -0.566 & -0.665 & -0.232 \\
\hline Q2: $(0.595,0.640]$ & 5 & 80.0 & 100 & 100 & 1.32 & 1.57 & 0.602 & 0.568 & 0.906 & 0.862 \\
\hline Q3: $(0.640,0.925]$ & 2 & $\overline{50.0}$ & $\overline{50.0}$ & 100 & 2.45 & 2.45 & 1.00 & 0.329 & 1.00 & 0.228 \\
\hline
\end{tabular}




\begin{tabular}{|c|r|r|r|r|r|r|r|r|r|r|}
\hline Q4: (0.925,3.300] & 7 & 57.1 & 85.7 & 100 & 0.973 & 1.78 & 0.641 & 0.641 & 0.675 & 0.674 \\
\hline fu $_{\mathbf{p}}$ & & & & & & & & & & \\
\hline Q1: (0.0002,0.0125] & 4 & 100 & 100 & 100 & 1.13 & 1.41 & 0.797 & 0.771 & 0.968 & 0.940 \\
\hline Q2: (0.0125,0.05] & 5 & 60.0 & 60.0 & 80.0 & 0.819 & 3.35 & -0.719 & -0.712 & -0.595 & -0.442 \\
\hline Q3: (0.05,0.0855] & 4 & 50.0 & 75.0 & 100 & 1.91 & 1.99 & 0.744 & 0.644 & 0.874 & 0.754 \\
\hline Q4: (0.0855,0.74] & 4 & 50.0 & 100 & 100 & 0.602 & 1.66 & 0.956 & 0.800 & 0.938 & 0.633 \\
\hline
\end{tabular}

Table A4: Summary statistics for $\mathrm{F}_{\text {rel }}$ predictions between p.o. and solution simulations,

grouped by different compound specific properties.

\begin{tabular}{|c|c|c|c|c|c|c|c|c|c|c|}
\hline & $\begin{array}{l}\text { no. } \\
\text { APIs }\end{array}$ & $\begin{array}{l}\text { \% } \\
\text { within } \\
2 \text { fold }\end{array}$ & $\begin{array}{l}\text { \% } \\
\text { within } \\
3 \text { fold }\end{array}$ & $\begin{array}{l}\text { \% } \\
\text { within } \\
10 \text { fold }\end{array}$ & AFE & AAFE & $\overline{\mathbf{R}}$ & $\mathrm{CCC}$ & $\begin{array}{l}R \\
\text { (of log } \\
\text { data) }\end{array}$ & $\begin{array}{l}\text { CCC } \\
\text { (of log } \\
\text { data) }\end{array}$ \\
\hline \multicolumn{11}{|l|}{ Molecular Weight } \\
\hline Q1: $(150,365 \mathrm{~g} / \mathrm{mol}]$ & 6 & 66.7 & 66.7 & 100 & 0.928 & 1.77 & -0.743 & -0.304 & -0.626 & -0.362 \\
\hline Q2: $(365,440 \mathrm{~g} / \mathrm{mol}]$ & 7 & 57.1 & 71.4 & 100 & 0.482 & 2.07 & 0.827 & 0.427 & 0.704 & 0.242 \\
\hline Q3: $(440,505 \mathrm{~g} / \mathrm{mol}]$ & 4 & 100 & 100 & 100 & 1.29 & 1.29 & 0.774 & 0.287 & 0.779 & 0.224 \\
\hline Q4: $(505,870 \mathrm{~g} / \mathrm{mol}]$ & 7 & 85.7 & 85.7 & 100 & 0.693 & 1.47 & 0.894 & 0.82 & 0.726 & 0.465 \\
\hline \multicolumn{11}{|l|}{ Acid/Base Nature } \\
\hline Acid & 3 & 100 & 100 & 100 & 0.868 & 1.35 & 0.466 & 0.136 & 0.523 & 0.113 \\
\hline Ampholyte & 2 & 50.0 & 50.0 & 100 & 1.56 & 2.07 & -1.00 & -0.527 & -1.00 & -0.351 \\
\hline Neutral & 3 & 66.7 & 66.7 & 100 & 0.578 & 1.73 & -0.986 & -0.352 & -0.968 & -0.462 \\
\hline Weak Base & 8 & 62.5 & 75.0 & 100 & 0.656 & 1.87 & 0.195 & 0.130 & 0.148 & 0.0671 \\
\hline Strong Base & 8 & 87.5 & 87.5 & 100 & 0.727 & 1.49 & 0.798 & 0.719 & 0.631 & 0.448 \\
\hline \multicolumn{11}{|l|}{$\log P$} \\
\hline Q1: $(-0.72,2.545]$ & 3 & 66.7 & 66.7 & 100 & 0.567 & 2.05 & -0.788 & -0.234 & -0.704 & -0.332 \\
\hline Q2: $(2.545,3.3]$ & 9 & 66.7 & 66.7 & 100 & 0.745 & 1.77 & 0.393 & 0.359 & 0.236 & 0.181 \\
\hline Q3: $(3.3,4.49]$ & 4 & 100 & 100 & 100 & 1.06 & 1.19 & 0.991 & 0.871 & 0.982 & 0.885 \\
\hline Q4: $(4.49,7.75]$ & 4 & 75.0 & 75.0 & 100 & 0.537 & 1.87 & 0.985 & 0.510 & 0.946 & 0.250 \\
\hline Not Given & 4 & 75.0 & 100 & 100 & 0.888 & 1.55 & -0.157 & -0.146 & -0.231 & -0.220 \\
\hline \multicolumn{11}{|l|}{$\overline{\log D}$} \\
\hline Q1: (-1.45,1.29] & 3 & 100 & 100 & 100 & 0.868 & 1.35 & 0.466 & 0.136 & 0.523 & 0.113 \\
\hline Q2: $(1.29,2.55]$ & 4 & 75.0 & 75.0 & 100 & 0.829 & 1.70 & 0.136 & 0.125 & 0.0478 & 0.0368 \\
\hline Q3: $(2.55,3.17]$ & 4 & 75.0 & 75.0 & 100 & 1.09 & 1.66 & 0.0683 & 0.0662 & -0.0243 & 0.0236 \\
\hline Q4: (3.17,5.8] & 4 & 50.0 & 75.0 & 100 & 0.606 & 1.88 & -0.392 & -0.179 & -0.341 & -0.214 \\
\hline Not Given & 9 & 77.8 & 77.8 & 100 & 0.624 & 1.68 & 0.853 & 0.762 & 0.744 & 0.485 \\
\hline \multicolumn{11}{|l|}{ BCS Classification } \\
\hline BCS class I & 3 & 66.7 & 66.7 & 100 & 1.38 & 1.66 & -0.49 & -0.278 & -0.476 & -0.185 \\
\hline BCS class II & 16 & 75 & 81.3 & 100 & 0.717 & 1.65 & 0.499 & 0.416 & 0.435 & 0.351 \\
\hline BCS class III & 1 & 100 & 100 & 100 & 0.784 & 1.28 & & & & \\
\hline BCS class IV & 4 & 75 & 75 & 100 & 0.537 & 1.87 & 0.985 & 0.51 & 0.946 & 0.25 \\
\hline \multicolumn{11}{|l|}{ Dose number } \\
\hline $\mathrm{D}_{0} \leq 1$ & 3 & 66.7 & 66.7 & 100 & 1.38 & 1.66 & -0.49 & -0.278 & -0.476 & -0.185 \\
\hline$D_{0}>1$ & 21 & 76.2 & 81 & 100 & 0.681 & 1.67 & 0.514 & 0.434 & 0.464 & 0.331 \\
\hline \multicolumn{11}{|l|}{ Estimated fa } \\
\hline $\mathrm{f}_{\mathrm{a}}<0.9$ & 8 & 87.5 & 87.5 & 100 & 0.681 & 1.56 & 0.555 & 0.457 & 0.61 & 0.324 \\
\hline$f_{a} \geq 0.9$ & 16 & 68.8 & 75 & 100 & 0.778 & 1.72 & 0.425 & 0.375 & 0.275 & 0.244 \\
\hline \multicolumn{11}{|l|}{ BP } \\
\hline Q1: (0 & 3 & 100 & 100 & 100 & 0.615 & 1.63 & 0.999 & 0.912 & 0.996 & 0.814 \\
\hline Q2: $(0.595,0.640]$ & 8 & 62.5 & 75.0 & 100 & 0.678 & 1.89 & -0.109 & -0.0845 & 0.0833 & 0.0609 \\
\hline
\end{tabular}




\begin{tabular}{|c|r|r|r|r|r|r|r|r|r|r|}
\hline Q3: (0.640,0.925] & 8 & 75.0 & 75.0 & 100 & 0.681 & 1.57 & 0.683 & 0.540 & 0.664 & 0.337 \\
\hline Q4: (0.925,3.300] & 5 & 80.0 & 80.0 & 100 & 1.11 & 1.52 & -0.0527 & -0.0156 & -0.174 & -0.0427 \\
\hline fu $_{\mathrm{p}}$ & & & & & & & & & & \\
\hline Q1: (0.0002,0.0125] & 5 & 60.0 & 80.0 & 100 & 0.611 & 1.80 & 0.576 & 0.303 & 0.689 & 0.187 \\
\hline Q2: (0.0125,0.05] & 8 & 75.0 & 75.0 & 100 & 0.674 & 1.66 & 0.515 & 0.416 & 0.454 & 0.363 \\
\hline Q3: (0.05,0.0855] & 6 & 66.7 & 66.7 & 100 & 0.988 & 1.89 & 0.275 & 0.271 & 0.161 & 0.151 \\
\hline Q4: (0.0855,0.74] & 5 & 100 & 100 & 100 & 0.755 & 1.33 & 0.709 & 0.493 & 0.757 & 0.589 \\
\hline
\end{tabular}

Table A5: Summary statistics for CL or CL/F predictions for i.v. and p.o. simulations, grouped by different compound specific properties.

\begin{tabular}{|c|c|c|c|c|c|c|c|c|c|}
\hline & $\begin{array}{l}\text { no. } \\
\text { APIs }\end{array}$ & $\begin{array}{l}\% \text { within } \\
2 \text { fold }\end{array}$ & $\begin{array}{l}\% \\
\text { within } 3 \\
\text { fold }\end{array}$ & $\begin{array}{l}\% \\
\text { within } \\
10 \text { fold }\end{array}$ & AFE & AAFE & $\mathbf{R}$ & $\mathrm{CCC}$ & $\begin{array}{l}R \\
\text { (of log } \\
\text { data) }\end{array}$ \\
\hline Molecular Weight & & & & & & & & & \\
\hline Q1: $(150,365 \mathrm{~g} / \mathrm{mol}]$ & 11 & 27.3 & 45.5 & 81.8 & 0.736 & 4.02 & 0.261 & 0.0852 & 0.382 \\
\hline Q2: $(365,440 \mathrm{~g} / \mathrm{mol}]$ & 10 & 40 & 50 & 80 & 1.45 & 3.70 & 0.668 & 0.607 & 0.524 \\
\hline Q3: $(440,505 \mathrm{~g} / \mathrm{mol}]$ & 11 & 27.3 & 36.4 & 100 & 0.375 & 3.51 & 0.448 & 0.181 & 0.626 \\
\hline Q4: $(505,870 \mathrm{~g} / \mathrm{mol}]$ & 11 & 36.4 & 45.5 & 90.9 & 0.553 & 3.48 & 0.613 & 0.0676 & 0.538 \\
\hline Acid/Base Nature & & +9 & & & & & & & \\
\hline Acid & 10 & 10.0 & 10.0 & 80.0 & 0.832 & 6.84 & -0.0331 & -0.0329 & 0.238 \\
\hline Ampholyte & 4 & 25.0 & 25.0 & 50.0 & 0.642 & 8.17 & 0.919 & 0.0712 & 0.468 \\
\hline Neutral & 5 & 40.0 & 60.0 & 100 & 0.430 & 2.33 & 0.856 & 0.116 & 0.791 \\
\hline Weak Base & 11 & 27.3 & 27.3 & 90.9 & 0.611 & 4.06 & 0.0307 & 0.0235 & 0.496 \\
\hline Strong Base & 13 & 53.8 & 84.6 & 100 & 0.754 & 1.95 & 0.756 & 0.754 & 0.801 \\
\hline $\log P$ & 2 & & & & & & & & \\
\hline Q1: $(-0.72,2.545]$ & 9 & 44.4 & 55.6 & 88.9 & 0.502 & 3.56 & 0.532 & 0.499 & 0.497 \\
\hline Q2: $(2.545,3.3]$ & 9 & 55.6 & 66.7 & 100 & 0.827 & 2.31 & 0.211 & 0.153 & 0.500 \\
\hline Q3: $(3.3,4.49]$ & 8 & 25.0 & 50.0 & 87.5 & 0.481 & 3.62 & 0.812 & 0.081 & 0.786 \\
\hline Q4: $(4.49,7.75]$ & 9 & 22.2 & 22.2 & 88.9 & 0.878 & 4.16 & 0.408 & 0.372 & 0.524 \\
\hline Not Given & 8 & 12.5 & 25.0 & 75.0 & 0.78 & 5.65 & 0.148 & 0.0884 & 0.422 \\
\hline \multicolumn{10}{|l|}{ LogD } \\
\hline Q1: (-1.45,1.29] & 7 & 14.3 & 28.6 & 71.4 & 0.459 & 7.08 & 0.721 & 0.0724 & 0.488 \\
\hline Q2: $(1.29,2.55]$ & 7 & 28.6 & 42.9 & 100 & 0.610 & 3.27 & 0.448 & 0.430 & 0.554 \\
\hline Q3: $(2.55,3.17]$ & 7 & 57.1 & 57.1 & 85.7 & 1.65 & 3.64 & 0.216 & 0.212 & 0.315 \\
\hline Q4: $(3.17,5.8]$ & 7 & 14.3 & 28.6 & 71.4 & 0.455 & 4.41 & 0.185 & 0.0734 & 0.795 \\
\hline Not Given & 15 & 40.0 & 53.3 & 100 & 0.672 & 2.63 & 0.203 & 0.169 & 0.516 \\
\hline \multicolumn{10}{|l|}{ BCS Classification } \\
\hline BCS class I & 8 & 37.5 & 62.5 & 87.5 & 1.23 & 2.83 & 0.177 & 0.0636 & 0.458 \\
\hline BCS class II & 24 & 29.2 & 37.5 & 87.5 & 0.567 & 3.91 & 0.428 & 0.423 & 0.528 \\
\hline BCS class III & 2 & 100 & 100 & 100 & 1.45 & 1.45 & 1 & 0.947 & 1 \\
\hline BCS class IV & 9 & 22.2 & 33.3 & 88.9 & 0.529 & 4.82 & 0.733 & 0.0794 & 0.596 \\
\hline \multicolumn{10}{|l|}{ Dose number } \\
\hline$D_{0} \leq 1$ & 8 & 37.5 & 62.5 & 87.5 & 1.23 & 2.83 & 0.177 & 0.0636 & 0.458 \\
\hline$D_{0}>1$ & 35 & 31.4 & 40 & 88.6 & 0.588 & 3.9 & 0.347 & 0.0885 & 0.545 \\
\hline \multicolumn{10}{|l|}{ Estimated fa } \\
\hline $\mathrm{f}_{\mathrm{a}}<0.9$ & 15 & 40 & 46.7 & 80 & 0.604 & 4 & 0.3 & 0.0661 & 0.585 \\
\hline
\end{tabular}




\begin{tabular}{|l|r|r|r|r|r|r|r|r|r|r|}
\hline $\mathbf{f}_{\mathbf{a}} \geq \mathbf{0 . 9}$ & 28 & 28.6 & 42.9 & 92.9 & 0.716 & 3.51 & 0.404 & 0.402 & 0.458 & \\
\hline $\mathbf{B P}$ & & & & & & & & & & \\
\hline Q1: (0.517,0.595] & 11 & 0.00 & 18.2 & 81.8 & 1.02 & 6.31 & 0.197 & 0.0464 & 0.435 & \\
\hline Q2: (0.595,0.640] & 9 & 11.1 & 11.1 & 66.7 & 0.298 & 7.00 & 0.189 & 0.123 & 0.231 & \\
\hline Q3: (0.640,0.925] & 12 & 50.0 & 58.3 & 100 & 0.577 & 2.35 & 0.537 & 0.243 & 0.730 & \\
\hline Q4: (0.925,3.300] & 11 & 63.6 & 81.8 & 100 & 1.03 & 2.05 & 0.793 & 0.790 & 0.624 & \\
\hline fu $_{\mathbf{p}}$ & & & & & & & & & & \\
\hline Q1: (0.0002,0.0125] & 11 & 18.2 & 18.2 & 63.6 & 0.53 & 6.68 & 0.0460 & 0.0356 & 0.362 & \\
\hline Q2: (0.0125,0.05] & 10 & 30.0 & 40.0 & 100 & 0.758 & 3.40 & 0.0589 & 0.0587 & 0.209 & \\
\hline Q3: (0.05,0.0855] & 11 & 36.4 & 63.6 & 100 & 0.445 & 2.66 & 0.648 & 0.580 & 0.824 & \\
\hline Q4: (0.0855,0.74] & 11 & 45.5 & 54.5 & 90.9 & 1.17 & 2.98 & 0.353 & 0.0553 & 0.523 & \\
\hline
\end{tabular}

Table A6: Summary statistics for $\mathrm{V}_{\mathrm{d}}$ or $\mathrm{V}_{\mathrm{d}} / \mathrm{F}$ predictions for i.v. and p.o. simulations, grouped

by different compound specific properties.

\begin{tabular}{|c|c|c|c|c|c|c|c|c|c|c|}
\hline & $\begin{array}{l}\text { no. } \\
\text { APIs }\end{array}$ & $\begin{array}{l}\% \\
\text { within } 2 \\
\text { fold }\end{array}$ & $\begin{array}{l}\% \\
\text { within } 3 \\
\text { fold }\end{array}$ & $\begin{array}{l}\% \\
\text { within } \\
10 \text { fold }\end{array}$ & AFE & AAFE & $\mathbf{R}$ & $\mathrm{CCC}$ & $\begin{array}{l}\text { R } \\
\text { (of log } \\
\text { data) }\end{array}$ & \\
\hline \multicolumn{10}{|l|}{ Molecular Weight } & \\
\hline Q1: $(150,365 \mathrm{~g} / \mathrm{mol}]$ & 11 & 27.3 & 63.6 & 100 & 1.33 & 2.94 & 0.895 & 0.189 & 0.804 & \\
\hline Q2: $(365,440 \mathrm{~g} / \mathrm{mol}]$ & 10 & 30.0 & 60.0 & 80.0 & 2.06 & 3.23 & 0.448 & 0.340 & 0.601 & \\
\hline Q3: $(440,505 \mathrm{~g} / \mathrm{mol}]$ & 11 & 36.4 & 72.7 & 90.9 & 0.968 & 2.6 & 0.308 & 0.270 & 0.637 & \\
\hline Q4: $(505,870 \mathrm{~g} / \mathrm{mol}]$ & 11 & 45.5 & 54.5 & 100 & 1.08 & 2.74 & 0.0893 & 0.0374 & 0.442 & \\
\hline \multicolumn{10}{|l|}{ Acid/Base Nature } & \\
\hline Acid & 10 & 10.0 & 40.0 & 90.0 & 1.52 & 4.87 & 0.306 & 0.141 & 0.616 & \\
\hline Ampholyte & 4 & 0.00 & 25.0 & 75.0 & 0.659 & 5.53 & 0.848 & 0.116 & 0.325 & \\
\hline Neutral & 5 & 60.0 & 80.0 & 100 & 1.76 & 1.90 & 0.920 & 0.378 & 0.924 & \\
\hline Weak Base & 11 & 36.4 & 63.6 & 90.9 & 1.33 & 2.62 & 0.146 & 0.046 & 0.707 & \\
\hline Strong Base & 13 & 53.8 & 84.6 & 100 & 1.2 & 1.96 & 0.694 & 0.687 & 0.670 & \\
\hline \multicolumn{10}{|l|}{$\log P$} & \\
\hline Q1: $(-0.72,2.545]$ & 9 & 33.3 & 66.7 & 100 & 0.917 & 2.67 & 0.637 & 0.596 & 0.802 & \\
\hline Q2: $(2.545,3.3]$ & 9 & 22.2 & 66.7 & 88.9 & 1.10 & 2.78 & 0.0359 & 0.0227 & 0.262 & \\
\hline Q3: $(3.3,4.49]$ & 8 & 50.0 & 75.0 & 100 & 1.14 & 2.42 & 0.452 & 0.0755 & 0.533 & \\
\hline Q4: $(4.49,7.75]$ & 9 & 44.4 & 55.6 & 88.9 & 2.43 & 3.15 & 0.263 & 0.131 & 0.511 & \\
\hline Not Given & 8 & 25.0 & 50.0 & 87.5 & 1.23 & 3.40 & 0.279 & 0.185 & 0.534 & \\
\hline \multicolumn{10}{|l|}{$\operatorname{LogD}$} & \\
\hline Q1: $(-1.45,1.29]$ & 7 & 28.6 & 57.1 & 100 & 0.725 & 3.47 & 0.376 & 0.113 & 0.705 & \\
\hline Q2: $(1.29,2.55]$ & 7 & 42.9 & 57.1 & 100 & 0.698 & 2.35 & 0.738 & 0.639 & 0.736 & \\
\hline Q3: $(2.55,3.17]$ & 7 & 14.3 & 42.9 & 71.4 & 1.73 & 4.67 & 0.0981 & 0.0884 & 0.251 & \\
\hline Q4: $(3.17,5.8]$ & 7 & 28.6 & 71.4 & 100 & 1.37 & 2.44 & 0.425 & 0.122 & 0.817 & \\
\hline Not Given & 15 & 46.7 & 73.3 & 93.3 & 1.89 & 2.45 & 0.437 & 0.358 & 0.601 & \\
\hline \multicolumn{10}{|l|}{ BCS Classification } & \\
\hline BCS class I & 8 & 37.5 & 62.5 & 100 & 1.12 & 2.75 & 0.909 & 0.172 & 0.622 & \\
\hline BCS class II & 24 & 29.2 & 66.7 & 87.5 & 1.31 & 2.86 & 0.347 & 0.319 & 0.65 & \\
\hline BCS class III & 2 & 50 & 50 & 100 & 1.71 & 3.28 & 1 & 0.463 & 1 & \\
\hline BCS class IV & 9 & 44.4 & 55.6 & 100 & 1.29 & 2.88 & 0.0934 & 0.0442 & 0.671 & \\
\hline \multicolumn{10}{|l|}{ Dose number } & \\
\hline $\mathrm{D}_{0} \leq 1$ & 8 & 37.5 & 62.5 & 100 & 1.12 & 2.75 & 0.909 & 0.172 & 0.622 & \\
\hline $\mathrm{D}_{0}>1$ & 35 & 34.3 & 62.9 & 91.4 & 1.33 & 2.89 & 0.194 & 0.185 & 0.644 & \\
\hline \multicolumn{10}{|l|}{ Estimated fa } & \\
\hline$f_{a}<0.9$ & 15 & 33.3 & 53.3 & 93.3 & 1.37 & 3.53 & 0.0441 & 0.0419 & 0.634 & \\
\hline
\end{tabular}




\begin{tabular}{|c|c|c|c|c|c|c|c|c|c|}
\hline $\mathbf{f}_{\mathrm{a}} \geq \mathbf{0 . 9}$ & 28 & 35.7 & 67.9 & 92.9 & 1.24 & 2.56 & 0.385 & 0.342 & 0.606 \\
\hline \multicolumn{10}{|l|}{$\mathbf{B P}$} \\
\hline Q1: $(0.517,0.595]$ & 11 & 36.4 & 45.5 & 81.8 & 2.34 & 4.25 & 0.0059 & 0.00519 & 0.635 \\
\hline Q2: $(0.595,0.640]$ & 9 & 11.1 & 44.4 & 88.9 & 1.18 & 3.74 & 0.338 & 0.314 & 0.686 \\
\hline Q3: $(0.640,0.925]$ & 12 & 33.3 & 75.0 & 100 & 0.907 & 2.17 & 0.612 & 0.378 & 0.664 \\
\hline Q4: (0.925,3.300] & 11 & 54.5 & 81.8 & 100 & 1.11 & 2.10 & 0.888 & 0.886 & 0.642 \\
\hline \multicolumn{10}{|l|}{$\mathbf{f u}_{\mathrm{p}}$} \\
\hline Q1: $(0.0002,0.0125]$ & 11 & 36.4 & 54.5 & 81.8 & 1.66 & 3.63 & 0.415 & 0.156 & 0.687 \\
\hline Q2: $(0.0125,0.05]$ & 10 & 30.0 & 70.0 & 100 & 1.61 & 2.55 & 0.311 & 0.224 & 0.550 \\
\hline Q3: $(0.05,0.0855]$ & 11 & 45.5 & 63.6 & 100 & 0.977 & 2.2 & 0.789 & 0.775 & 0.771 \\
\hline Q4: $(0.0855,0.74]$ & 11 & 27.3 & 63.6 & 90.9 & 1.07 & 3.25 & -0.0327 & -0.0301 & 0.472 \\
\hline
\end{tabular}

